\title{
COMO AS EMPRESAS DO SETOR DA CONSTRUÇÃO ESTÃO ORGANIZADAS?
}

\author{
How the construction companies are organized?
}

\author{
Alfredo larozinski Neto', Angela Rosi Docena Alencar ${ }^{2}$, Alessandra Tourinho Maia ${ }^{3}$
}

Recebido em 16 de março de 2016; recebido para revisão em 27 de maio de 2016; aceito em 28 de agosto de 2016; disponível on-line em 13 de março de 2017.

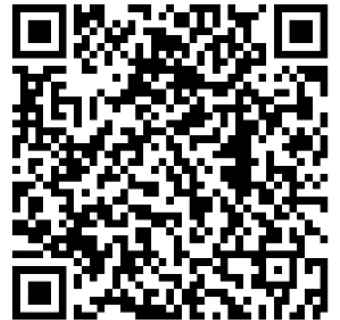

\section{PALAVRAS CHAVE:}

Características organizacionais; Construção civil; Teoria da organização; Gestão da construção; Estrutura organizacional.

\section{KEYWORDS:}

Organizational characteristics; Construction; Organization theory; Construction management; Organizational structure.

\section{* Contato com os autores:}

${ }^{1}$ e-mail: alfredo.iarozinsk@gmail.com (A. I. Neto)

Engenheiro Mecânico, Doutor em Ciências pela Université Paul Cezanne - FR, Professor do Programa de Pós-Graduação em Engenharia Civil da Universidade Tecnológica Federal do Paraná -UTFPR.

2e-mail: angelasaponga@hotmail.com (A. R. D. Alencar)

Administradora, Mestre em Engenharia Civil pela UTFPR, Professora do Curso de Administração da UNIGUAÇU.

${ }^{3}$ e-mail: alessandra.tourinho@gmail.com (A. T. Maia)

Engenheira Civil, Mestre em Engenharia Civil pela UTFPR, Professora do Curso de Engenharia Civil da Universidade Positivo. 


\section{INTRODUÇÃO}

A construção civil desempenha um papel importante no contexto econômico do país, uma vez que representa em torno de $6 \%$ do PIB nacional e emprega cerca de $40 \%$ da mão de obra industrial (IBGE, 2011). Apesar da importância deste setor na economia, sua evolução e modernização não acontecem na mesma intensidade que os outros segmentos industriais (IETEC, 2014; PRESCOT, 2014). O setor da construção civil apresentou um forte desenvolvimento dos últimos dez anos. A maior demanda e concorrência no setor têm trazido alguns desafios para o ramo, que tenta se adaptar às exigências do mercado atual e às peculiaridades da construção caracterizada por ciclos de negócios extensos e da alta complexidade de sua operação.

Tal conjuntura tem levado as organizações a buscar maior eficácia em suas estruturas, uma vez que o mercado está cada vez mais competitivo, exigindo maior flexibilidade na adaptação dos processos de negócio para que as organizações sustentem fatores críticos de sucesso em seus ambientes de competição (SANTOS, 2002). A configuração organizacional está diretamente associada à eficiência da gestão das empresas do setor (ZAYED et al., 2012). Entretanto, o setor da construção civil é frequentemente identificado com severas deficiências em termos de gestão, grandes taxas de desperdícios e baixa produtividade na execução de suas atividades (LANNES e FARIA, 2004). As diferentes formas de como as empresas do setor estão organizadas tem um impacto direto em todos estes aspectos. Assim sendo, a compreensão do funcionamento das empresas do setor da construção é necessária para identificar deficiências e orientar possíveis estratégias de desenvolvimento do setor. Portanto, o objetivo principal deste trabalho é de entender como se configuram as principais características organizacionais das empresas do setor da construção civil.

O objetivo do presente trabalho é entender as características organizacionais das empresas do setor da construção a fim de se estabelecer um perfil representativo dessas empresas visando identificar as deficiências em relação ao que é preconizado como as melhores práticas organizacionais.

\section{OS ESTUDOS ORGANIZACIONAIS RELACIONADOS AO SETOR DA CONSTRUÇÃO}

Os estudos referentes à organização das empresas da construção civil começaram a ser publicados em meados dos anos 1980. Entre eles, o mais relevante é o trabalho de Chang e Choi (1988) que relaciona o impacto da estratégia adotada e os tipos de estruturas organizacionais no desempenho de empresas Coreanas do setor da construção.

Durante os anos 1990 e início dos anos 2000 houve um aprofundamento das pesquisas com foco em temas específicos relacionados à Teoria das Organizações. O trabalho de Lansley (1994) é um dos primeiros a se destacar na aplicação dos conceitos da Teoria das Organizações, no entendimento e na análise do funcionamento de empresas da construção civil. O autor aborda o impacto dos estilos de liderança e da estrutura organizacional no desempenho global da empresa.

Shirazi et al. (1996) sugerem uma maior descentralização da estrutura de gestão em função da complexidade das atividades da construção civil. No mesmo sentido Kim (1997) apresenta um estudo que mostra a necessidade de descentralização e flexibilização das estruturas organizacionais das empresas de construção em face da complexidade dos projetos e exigências do ambiente concorrencial. Cabe destacar, também, o trabalho de Handa e Adas (1996), um dos pioneiros nas pesquisas que relacionam as características organizacionais e a eficácia organizacional. Este estudo utiliza um modelo de múltiplas variáveis com o objetivo de predizer o nível de eficácia organizacional nas empresas de construção. Outro estudo de destaque neste tema é o apresentado por Dikmen et al. (2005). Esta pesquisa, fundamentada em dados coletados em 116 empresas de construção localizadas na Turquia, a partir de uma pesquisa Survey, procura identificar os principais parâmetros relacionados à eficácia organizacional.

Benson (2010) investigou a gestão da flexibilidade organizacional de empresas de construção em Cingapura. Segundo o autor, a 
flexibilidade pode ser influenciada, em diferentes graus, pelos seguintes fatores determinantes: cultura de aprendizagem organizacional, estrutura organizacional, aptidões e comportamento dos trabalhadores, capacidades da cadeia de suprimentos e estratégias de negócios.

O trabalho de Cheung et al. (2012) apresenta o impacto da estrutura organizacional no incremento dos fluxos de informações e na comunicação para melhorar o desempenho das empresas de construção Australianas. Os autores citam que a influência da cultura e da organização sobre o desempenho das empresas de construção está se tornando um tema cada vez mais relevante para o estabelecimento de parcerias.

O trabalho de Zayed et al. (2012) analisa, através de redes neurais artificias, o desempenho das organizações de construção civil através de um conjunto de 18 fatores, que vão além dos aspectos financeiros. Listados por ordem de significância, os dez primeiros fatores, considerados críticos de sucesso são: disponibilidade de conhecimento, clareza da visão, missão e objetivos, estrutura organizacional, avaliação de feedback, experiência no negócio, condições políticas, pesquisa e desenvolvimento, cultura dos funcionários e estratégia de competição.

A análise da literatura acerca do tema mostra que o aspecto comum a estas publicações é a clara relação existente entre as variáveis organizacionais e o desempenho das empresas de construção civil.

\section{ESTRATÉGIA DA PESQUISA}

Para efeito desta pesquisa, a investigação foi delimitada às características organizacionais de empresas de construção civil, localizadas em Curitiba e região metropolitana, no Estado do Paraná, que tem como atividade principal os seguintes setores de atuação: execução de obras residenciais, edificações industriais e comerciais, obras de infraestrutura, serviços especializados para a construção civil, fabricação de estruturas prémoldadas em concreto armado e/ou fabricação de artefatos de cimento para uso na construção.

A base metodológica da pesquisa é o
Survey aliado à análise estatística descritiva. $\mathrm{O}$ Survey visa à obtenção de dados primários sobre características, ações ou opiniões de determinado grupo de pessoas, indicado como representante de uma população alvo, por meio de um instrumento de pesquisa, pré-definido, normalmente um questionário. (HAIR JR. et al., 2005). A Figura 1 apresenta as principais etapas da estratégia metodológica adotada. A apresentação do problema e a revisão bibliográfica foram apresentadas em seções anteriores. O desenvolvimento do Método Survey e os procedimentos de análise dos dados são descritos a seguir.

\subsection{PLANEJAMENTO DO SURVEY}

O planejamento do Survey foi dividido em cinco etapas: a definição das necessidades de informação; a identificação das variáveis; a definição da população alvo e amostra; a seleção do método para coleta dos dados e o desenvolvimento do instrumento de coleta e mensuração de dados.

Para que se inicie o planejamento de um Survey é necessário definir os dados que serão coletados de modo a gerar informações acerca do tema pesquisado. Nesta pesquisa houve preocupação em se levantar dados associados às características organizacionais destacadas nos trabalhos dos seguintes autores: Woodward (1965), Vasconcelos e Hemsley (2002), Mintzberg (2003), Ozaki (2003) e Hall (2004).

A partir dos modelos apresentados pelos autores citados acima foi possível identificar as principais variáveis relacionadas às características organizacionais de uma empresa. De modo a simplificar a análise, essas variáveis foram divididas em dois grupos homogêneos e cinco fatores, como mostra o Quadro 1.

O primeiro grupo de variáveis é formado pelas variáveis independentes. Neste grupo, o "valor" das variáveis é resultado de uma escolha feita por aqueles que possuem poder dentro das empresas. As escolhas efetuadas estabelecem uma determinada configuração para o sistema organizacional da empresa. Este grupo é formado pela estrutura, forma de gestão e formação de pessoal. O segundo grupo, que representa as 
variáveis dependentes, é formado por características que supostamente são resultado de uma configuração organizacional anteriormente definida. Este grupo é formado pelos seguintes fatores: relações humanas e flexibilidade.

A definição da população alvo desta pesquisa foi constituída por empresas com atividades vinculadas à construção civil, localizadas em Curitiba e região metropolitana. Em função do grande número de empresas de construção civil com sede na região delimitada para esta amostra e da dificuldade de adesão da totalidade destas empresas à pesquisa, optou-se pelo método de amostragem não probabilística por conveniência. Este tipo de amostra envolve a seleção de elementos de amostra que estejam mais disponíveis para tomar parte no estudo e que podem oferecer as informações necessárias (HAIR JR. et al., 2005). Desta forma, a amostra de empresas selecionadas na presente pesquisa não pode ser considerada como representativa da população alvo, não sendo possível efetuar extrapolações e generalizações acerca dos resultados.

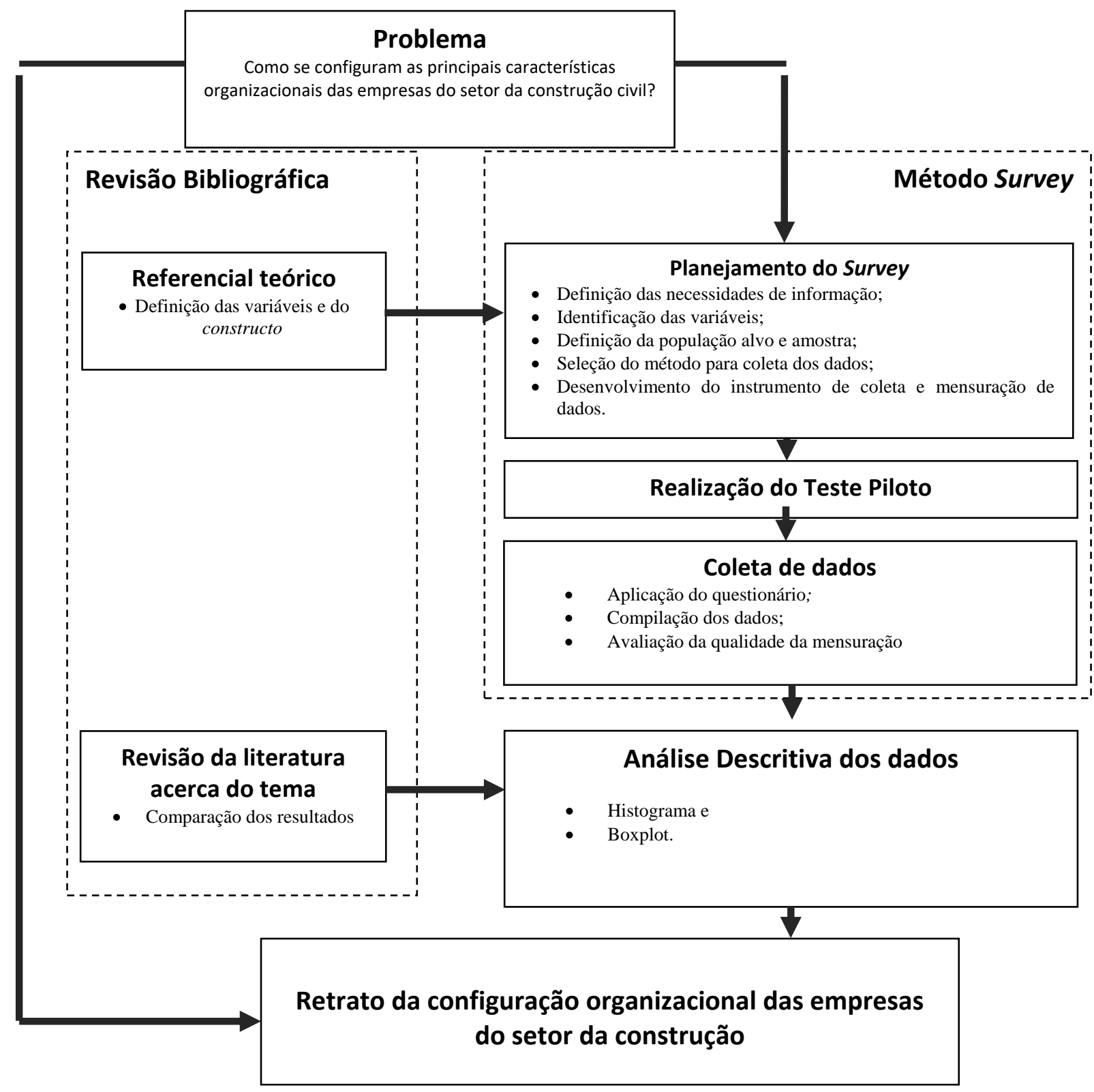

FIGURA 1: Estratégia da pesquisa 


\begin{tabular}{|c|c|c|}
\hline Grupo & Fator & Variável \\
\hline \multirow{3}{*}{$\begin{array}{c}\text { Variáveis } \\
\text { independentes }\end{array}$} & $\begin{array}{c}\text { Estrutura } \\
\text { organizacional }\end{array}$ & $\begin{array}{l}\text { Nível de centralização da estrutura organizacional } \\
\text { Nível de formalização dos cargos e funções } \\
\text { Nível de formalização das atividades e processos } \\
\text { Nível de hierarquização }\end{array}$ \\
\hline & Forma de Gestão & $\begin{array}{l}\text { Estilo de gestão da empresa } \\
\text { Nível de Integração entre os processos } \\
\text { Nível de controle exercido sobre as atividades e funcionários } \\
\text { Grau de autonomia dos funcionários }\end{array}$ \\
\hline & Formação de pessoal & $\begin{array}{l}\text { Média de horas de treinamento/ano } \\
\text { Nível de formação dos funcionários } \\
\text { Nível de polivalência dos funcionários }\end{array}$ \\
\hline \multirow{2}{*}{$\begin{array}{c}\text { Variáveis } \\
\text { dependentes }\end{array}$} & $\begin{array}{l}\text { Relações humanas } \\
\text { (clima } \\
\text { organizacional) }\end{array}$ & $\begin{array}{l}\text { Nível de cooperação entre os funcionários } \\
\text { Nível de interação entre os funcionários (troca de informações) } \\
\text { As relações entre funcionários formais/informais }\end{array}$ \\
\hline & Flexibilidade & $\begin{array}{l}\text { Capacidade da empresa em se adaptar as mudanças do seu mercado } \\
\text { Protagonismo em relação a seguir as tendências de mercado ou } \\
\text { anteciparem-se às mudanças } \\
\text { Tempo de resposta da empresa as demandas de mercado }\end{array}$ \\
\hline
\end{tabular}

O instrumento de coleta de dados adotado é um questionário, estruturado em duas partes: perfil das empresas e do entrevistado e características organizacionais.

A parte relacionada ao perfil das empresas e do entrevistado é composta por questões discursivas e de múltipla escolha, que compreendem a identificação do perfil da organização e do entrevistado, com destaque para o setor de atividade principal, o ano de fundação da empresa, a região de atuação, o número de funcionários, a forma de constituição e de administração, o número de certificações, a produção anual, assim como a área de formação do respondente e o seu tempo de atuação profissional na empresa avaliada.

A parte relativa às características organizacionais é composta por 20 questões fechadas relacionadas às variáveis apresentadas no Quadro 1. Cada questão foi associada a uma variável identificada a partir do estudo da Teoria das Organizações. Estas variáveis procuraram refletir o nível de centralização e formalização, o estilo de liderança, o grau de autonomia, os critérios de departamentalização, o número anual de horas de treinamento, dentre outras características.

A mensuração quantitativa destas características se deu através da adoção de uma escala de diferencial semântico de sete pontos. A escala utilizada fornece variáveis classificadas com ordinais. Elas são representadas por números que representam uma ordem de importância subjacente às características da variável. De acordo com Aguiar et al. (2011), escalas de diferencial semântico são aquelas onde cada item avaliado é polarizado em dois adjetivos (ou frases descritivas) opostos e contrários. A escala adotada nesta pesquisa, exemplificada no Quadro 2, é composta por sete graus, postos entre dois adjetivos ou frases descritivas antônimas em que o respondente deve escolher o grau que melhor representa sua opinião. 0 valor 4 representa o ponto neutro em relação aos dois adjetivos antagônicos.

É importante destacar que, em função da forma de mensuração, o emprego de escalas acrescenta um caráter subjetivo às análises (SAMARTINI, 2006). Portanto, os resultados finais obtidos devem ser analisados como tendências e não como valores absolutos. 


\subsection{TESTE PILOTO DO QUESTIONÁRIO}

O teste piloto do questionário foi realizado em uma amostra de dez empresas da populaçãoalvo. Na ocasião, o questionário foi aplicado pessoalmente pelos pesquisadores permitindo uma análise global da exatidão e da coerência das respostas. Nesta etapa foi possível identificar algumas dúvidas em relação às questões e termos usados na escala de mensuração. Após o pré-teste, alguns ajustes foram efetuados para que se iniciasse a aplicação do questionário.

\subsection{COLETA DE DADOS}

Em torno de 450 empresas foram previamente contatadas e convidadas a participar desta pesquisa, cuja meta mínima de amostragem prevista era de 100 empresas. A amostra final, no entanto, é constituída por 125 empresas. A coleta de dados perdurou oito meses, no período compreendido entre novembro de 2013 e julho de 2014.

Cerca de $15 \%$ da amostra foi obtida através do envio eletrônico de questionários auto administrados, gerenciados por intermédio da ferramenta Formulários Google, às empresas de construção civil, localizadas na região de Curitiba, integrantes da base de dados da Regional Sul da Associação Brasileira de Cimento Portland (ABCP). Com a finalidade de garantir a confiabilidade dos dados coletados, preliminarmente contatou-se a alta direção destas empresas. A partir da sua anuência e da indicação de possíveis respondentes, o questionário era apresentado e o link para a resposta, disponibilizado.

Os demais questionários foram obtidos durante as aulas dos cursos pós-graduação da Universidade Tecnológica Federal do Paraná (UTFPR) e do Serviço Nacional de Aprendizagem Industrial (SENAI-PR) cujos alunos integravam o quadro funcional de empresas que se adequavam na descrição da população-alvo. Nesta etapa, os objetivos da pesquisa e o questionário foram apresentados pessoalmente pelos pesquisadores, que permaneceram disponíveis para elucidar quaisquer dúvidas que pudessem surgir durante o preenchimento.

\subsection{ANÁLISE DESCRITIVA DOS DADOS}

A análise descritiva de dados é um campo da estatística tem como objetivo sintetizar um conjunto de dados numéricos ou não, de forma a permitir uma visão global do comportamento desses dados (GUEDES, 2005; BUSSAB e MORETTIN, 2011). Como instrumentos para análise descritiva foram escolhidos dois tipos de gráficos: o histograma e o gráfico boxplot. Os gráficos são os formatos visuais de apresentação dos dados, empregados para representar um fenômeno, de forma a produzir uma impressão mais rápida, para destacar tendências expressadas por meio de números ou estatísticas (MILONE, 2004; GUEDES, 2005; PASQUALI, 2009).

\section{ANÁLISE DOS RESULTADOS}

O objetivo dessa etapa é analisar as características organizacionais das empresas que compõem a amostra a partir da análise descritiva dos dados. Segundo Hair et al. (2005), através da análise descritiva é possível, a partir da avaliação de um conjunto de respostas, obter algumas descobertas iniciais e descrever e analisar as características ou relações entre os fenômenos analisados. Assim, a análise descritiva utilizada teve por finalidade permitir um entendimento global das características organizacionais das empresas pesquisadas.

A análise dos dados baseou-se em uma amostra de 125 empresas do setor da construção civil. O Quadro 3 apresenta o resumo dos principais aspectos que caracterizam esta amostra.

\subsection{ANÁLISE DAS VARIÁVEIS INDEPENDENTES}

O grupo das variáveis independentes é formado por características organizacionais que são fixadas por decisão de cada empresa. Ele é subdividido em estrutura organizacional, forma de gestão e formação de pessoal. 


\begin{tabular}{|c|c|}
\hline \multicolumn{2}{|r|}{$\begin{array}{l}\text { QUADRO 3: Perfil da amostra. } \\
\text { PERFIL DA ORGANIZAÇÃO }\end{array}$} \\
\hline $\begin{array}{l}\text { Subsetor de } \\
\text { atuação }\end{array}$ & $\begin{array}{l}\text { 41,6\% da amostra correspondem a construtoras que atuam no segmento residencial, } 14,4 \% \text { de } \\
\text { construtoras que atuam no ramo de infraestrutura, } 13,6 \% \text { de empresas que atuam no ramo de } \\
\text { execução de edificações industriais, comerciais e outras edificações não residenciais. } 16,8 \% \text { das } \\
\text { empresas atuam no ramo de serviços especializados, os outros } 13,6 \% \text { da amostra são } \\
\text { representados pelas empresas classificadas como construção industrializada (fabricação de } \\
\text { estruturas pré-moldadas em concreto armado e/ou pela fabricação de artefatos de cimento). }\end{array}$ \\
\hline $\begin{array}{l}\text { Porte das } \\
\text { empresas }\end{array}$ & $\begin{array}{l}29,6 \% \text { são microempresas, } 20,8 \% \text { são pequenas empresas, } 17,6 \% \text { são empresas de grande } \\
\text { porte e } 16 \% \text { são empresas médias. } 16 \% \text { dos entrevistados não responderam a esta questão. }\end{array}$ \\
\hline $\begin{array}{l}\text { Tipo de } \\
\text { administração }\end{array}$ & $\begin{array}{l}44 \% \text { das empresas são consideradas familiares, } 48 \% \text { possuem administração profissional e os } \\
8 \% \text { restantes, administração mista. }\end{array}$ \\
\hline Constituição & $\begin{array}{l}78,4 \% \text { das empresas são do tipo limitadas, } 10,4 \% \text { são S/A de capital fechado, } 4,8 \% \text { S/A de } \\
\text { capital aberto, } 1 \% \text { S/A de capital misto e os } 5,4 \% \text { restantes são classificadas como outros. }\end{array}$ \\
\hline \multicolumn{2}{|r|}{ PERFIL DO ENTREVISTADO } \\
\hline $\begin{array}{l}\text { Área de } \\
\text { atuação do } \\
\text { entrevistado }\end{array}$ & $\begin{array}{l}\text { Quanto à área de atuação do respondente na estrutura da organização a amostra ficou } \\
\text { concentrada nas áreas de engenharia e desenvolvimento } 64,8 \% \text {, administrativa } 18,4 \% \text {, } \\
\text { produção e outros com } 5,6 \% \text { e comercial } 2,4 \% \text {. }\end{array}$ \\
\hline $\begin{array}{l}\text { Cargo ocupado } \\
\text { pelo } \\
\text { entrevistado }\end{array}$ & $\begin{array}{l}\text { Em relação ao cargo ocupado pelo respondente, a maior concentração é de engenheiros } \\
29,6 \% \text {, diretores } 19,2 \% \text {, gerentes das empresas } 13,6 \% \text {. Em seguida vêm os estagiários } 7,2 \% \text {, } \\
\text { arquitetos } 6,4 \% \text {, coordenadores } 6,4 \% \text {. Auxiliares, trainees, assessores, analistas, técnicos, } \\
\text { operadores e outros somam } 17,6 \% \text { da amostra. }\end{array}$ \\
\hline $\begin{array}{l}\text { Tempo de } \\
\text { atuação do } \\
\text { entrevistado } \\
\text { na empresa }\end{array}$ & $\begin{array}{l}79 \% \text { das respostas concentram-se no tempo médio de atuação de três anos na empresa. Em } \\
8 \% \text { das empresas, o tempo de atuação do respondente na organização varia entre sete e dez } \\
\text { anos, em } 3 \% \text { entre } 11 \text { e } 15 \text { anos, } 6 \% \text { entre } 16 \text { e } 20 \text { anos e apenas } 4 \% \text { dos respondentes } \\
\text { trabalham na empresa a mais de } 20 \text { anos. }\end{array}$ \\
\hline
\end{tabular}

FONTE: Autores (2016)

\subsubsection{Análises das variáveis relacionadas à estrutura organizacional}

A estrutura organizacional é a maneira como os elementos estão formalmente dispostos e relacionados em uma organização. Na pesquisa, o fator estrutura organizacional é constituído por quatro variáveis: nível de centralização da estrutura organizacional, nível de hierarquização, nível de formalização dos cargos e funções e nível de formalização das atividades e processos.

A Figura 3 mostra o gráfico de distribuição de frequência do nível de centralização. Os dados mostram que há uma forte centralização da estrutura e uma alta hierarquização nas empresas do setor da construção. A centralização é mais pronunciada com valores concentrados na parte superior da escala do gráfico. A Figura 4 mostra gráfico do nível de hierarquização da estrutura organizacional das empresas. O nível de hierarquização tem uma maior concentração das respostas no valor 5 da escala. Os resultados para estas duas variáveis podem ser considerados negativos para as empresas do setor, pois para estruturas organizacionais mais modernas se preconizam níveis menores, tanto de centralização, como de hierarquização (SANT'ANNA et al., 2008). 


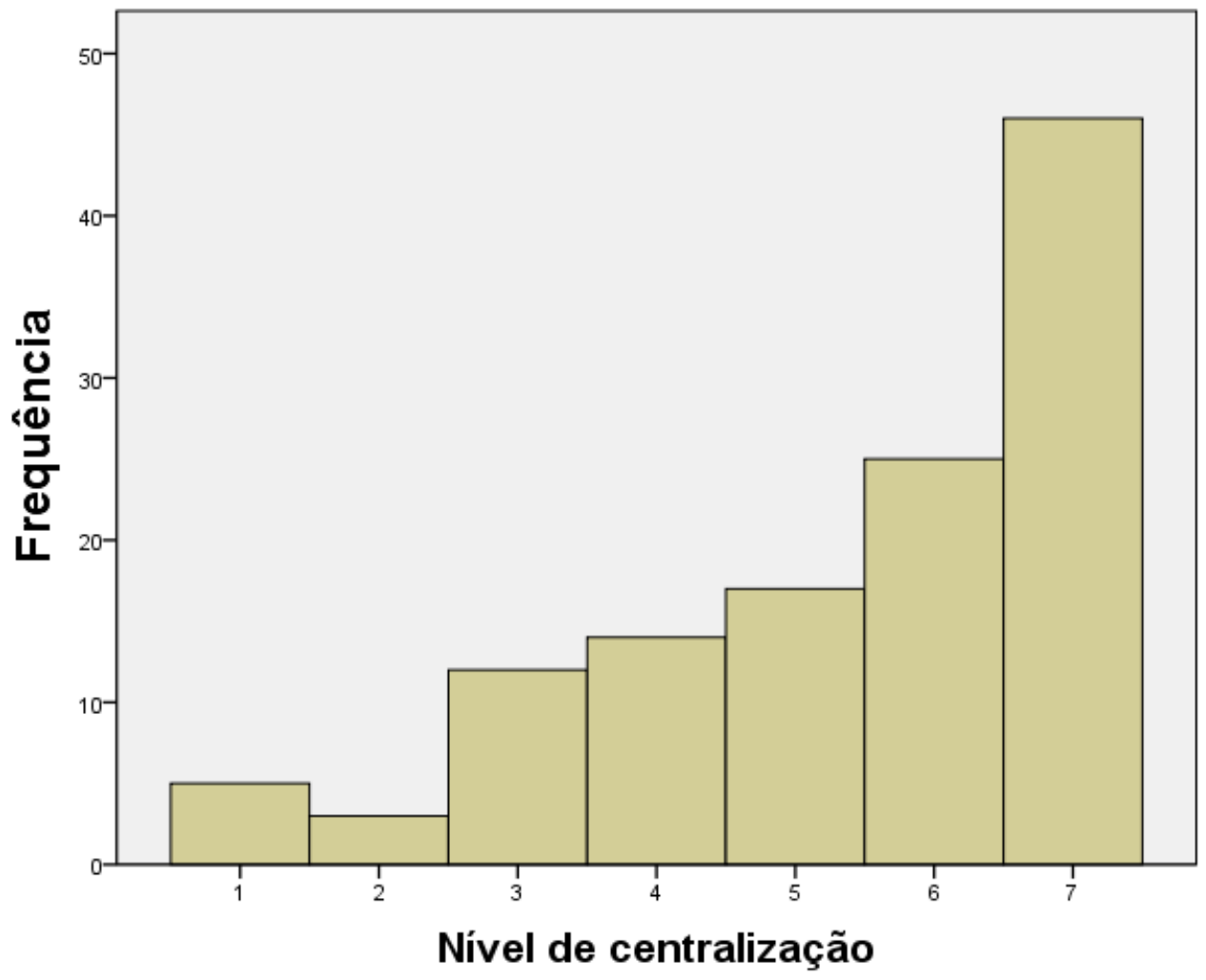

FIGURA 3: Distribuição de frequência do nível de centralização FONTE: Autores (2016).

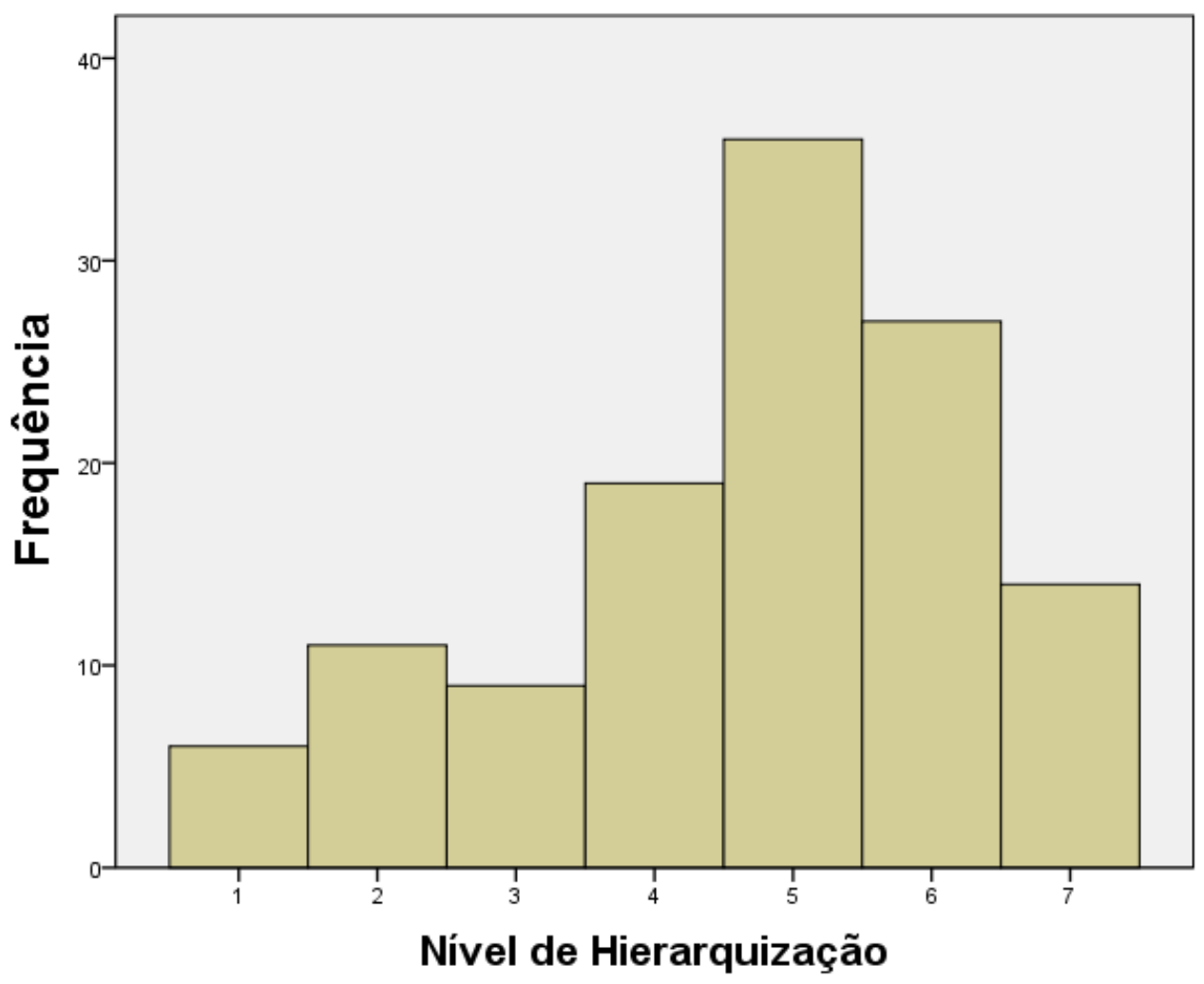

FIGURA 4: Distribuição de frequência do nível de hierarquização FONTE: Autores (2016).

Nas Figuras 5 e 6 apresenta-se, respectivamente os gráficos de distribuição de frequências do nível de formalização de cargos e funções e do nível de formalização de atividades e processos. A partir destes, é possível observar que as empresas do setor da construção civil possuem níveis de 
formalização elevados tanto para cargos e funções quanto para atividades e processos. As distribuições são semelhantes com uma concentração de respostas entre os valores 4 a 6 da escala.

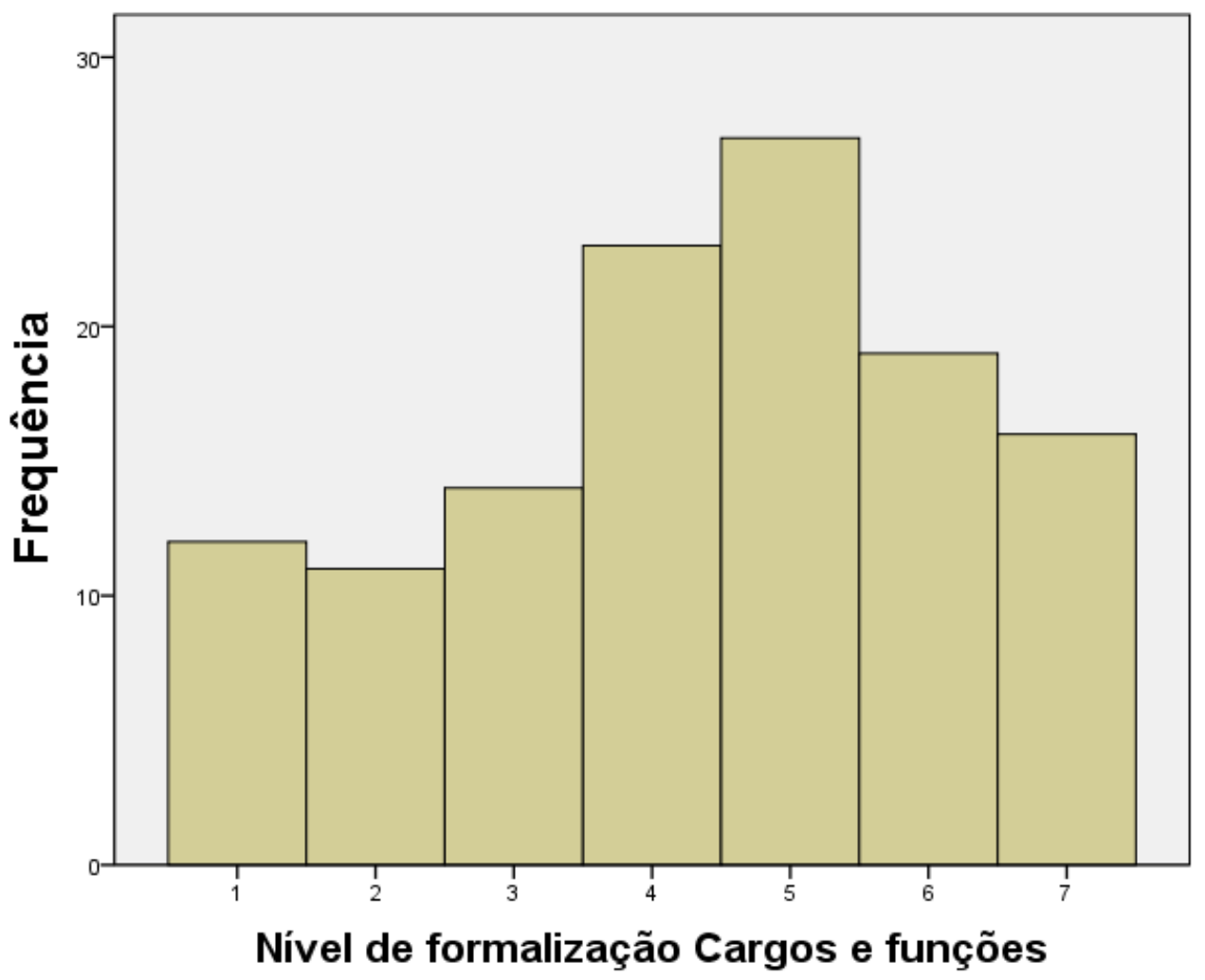

FIGURA 5: Distribuição de frequência do nível de formalização de cargos e funções FONTE: Autores (2016).

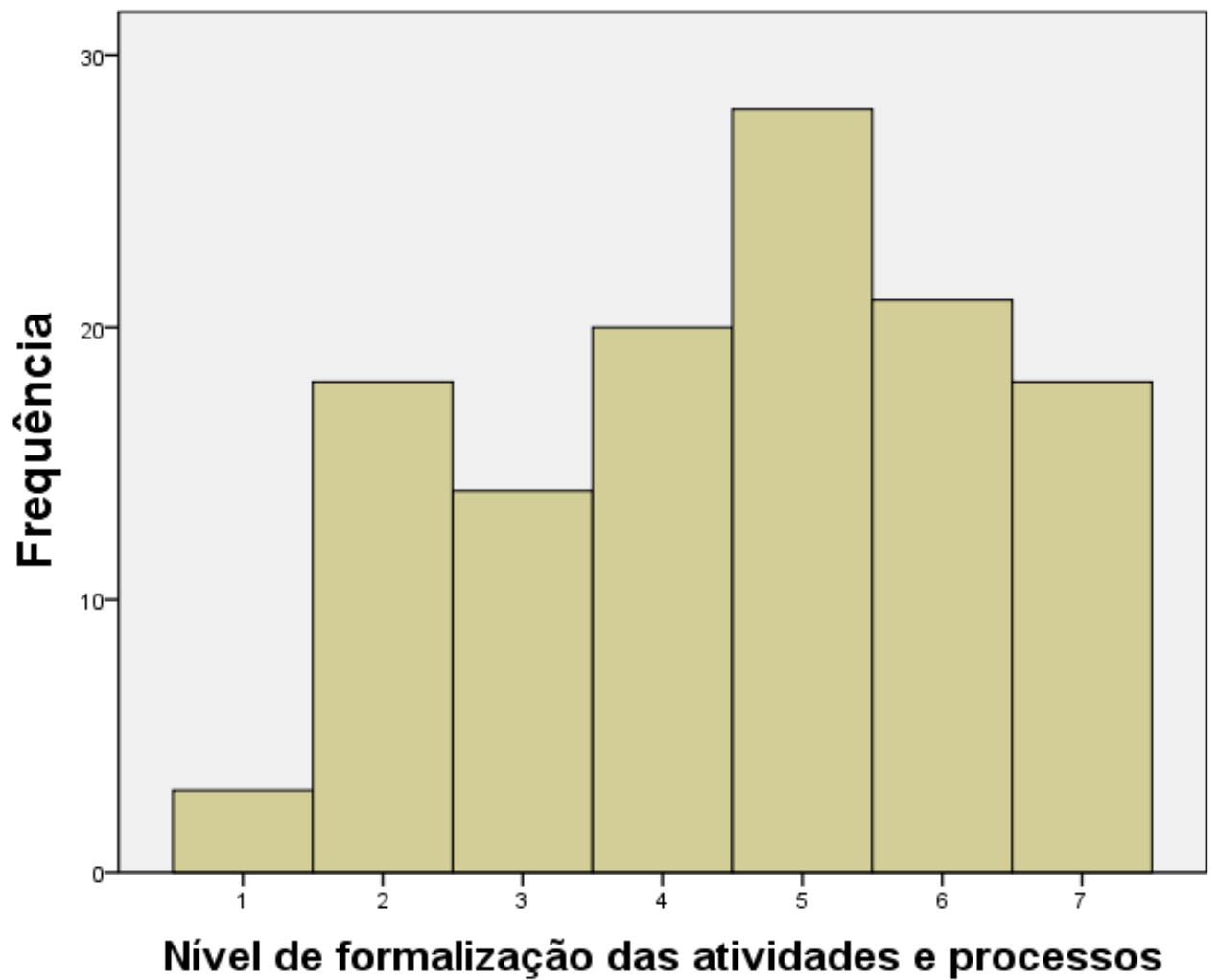

FIGURA 6: Distribuição de frequência do nível de formalização das atividades e processos FONTE: Autores (2016). 
Para Hall (1984), a formalização evidencia o uso de normas e procedimentos usados para administrar os desafios enfrentados pela organização. Uma empresa pode apresentar alto grau de formalização se suas normas forem altamente restritivas e seus procedimentos altamente formalizados. Já um baixo grau de formalização pode ser caracterizado por pouco ou nenhum procedimento estabelecido. Para Vasconcelos (1989) se a formalização for muito grande produzirá burocratização e a falta de agilidade da organização. Por outro lado, se a formalização for pequena ou inexistente levará a conflitos, duplicações de esforços e ineficiência.

O nível de formalização das empresas do setor da construção tende a ser de médio para alto. Estes parâmetros são adequados às necessidades de coordenação das funções e atividades típicas das empresas deste setor. Este nível de formalização auxilia os gestores na coordenação das atividades sem dificultar a comunicação entre os envolvidos e o fluxo de informação. Entretanto, o aspecto negativo reside na dispersão dos valores apresentados pelos gráficos.

A Figura 7 mostra os gráficos boxplot das variáveis relacionadas à estrutura organizacional. $A$ partir da análise conjunta dos gráficos é possível observar o comportamento das variáveis e realizar uma análise comparativa entre elas. Assim, pode-se destacar a tendência a um nível de centralização elevado e uma concentração das respostas acima da média para o nível de hierarquização. Para a centralização há uma maior dispersão entre as empresas do setor. $O$ nível hierarquização apresenta uma diferença interquartil menor que as demais variáveis mostrando que a hierarquização elevada é uma característica marcante das empresas da construção. A pouca dispersão dos valores dos níveis de hierarquização mostra uma situação bem consolidada para esta variável nas empresas do setor. Os níveis de formalização apresentam os valores de mediana semelhantes e acima da média. Porém, os dados estão mais dispersos, indicando uma variação maior para estas variáveis.

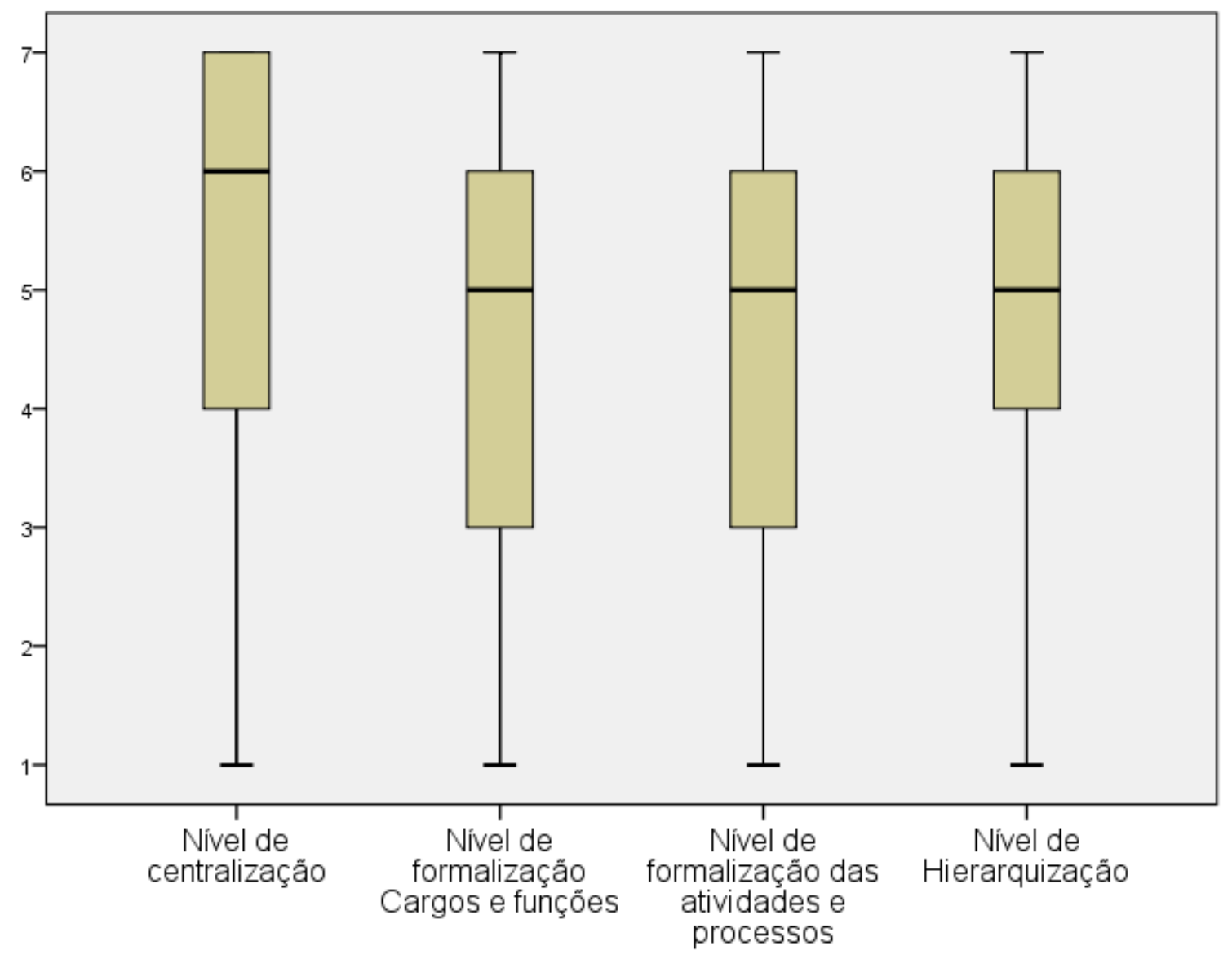

FIGURA 7: Gráficos boxplot das variáveis de estrutura FONTE: Autores (2016). 


\subsubsection{Análises das variáveis relacionadas à forma de gestão}

As variáveis associadas ao fator "forma de gestão" foram definidas como: estilo de gestão, nível de integração dos processos, nível de controle sobre as atividades dos funcionários e nível de autonomia dos funcionários.

No gráfico da Figura 8, é possível observar que a maior parte das empresas do setor da construção civil tende a apresentam um estilo de gestão mais autocrático. $O$ valor 1 (um) corresponde a um estilo autocrático e o valor 7 (sete) a um estilo democrático. As respostas estão agrupadas entre os valores 2 e 5 da escala. A autocracia ocorre onde o poder é mais concentrado em uma única pessoa ou em pequeno grupo. $O$ viés autocrático é compatível com a estrutura centralizada apresentada pelas empresas. Entretanto, para ambientes dinâmicos como do setor da construção preconiza-se estruturas mais descentralizadas e modos mais participativos de gestão (HARRIS e MCCAFFER; 2013).

No gráfico da Figura 9, verifica-se que grande parte das organizações pesquisadas apresentam um alto nível de integração entre os processos. Os dados estão concentrados entre as escalas 4 a 6 , com um destaque para o valor 5 , corroboram com essa análise. O alto nível de integração é decorrente, provavelmente, da interdependência e da natureza sequencial das atividades da construção. Ela é uma imposição associada às características próprias de execução das atividades de construção.

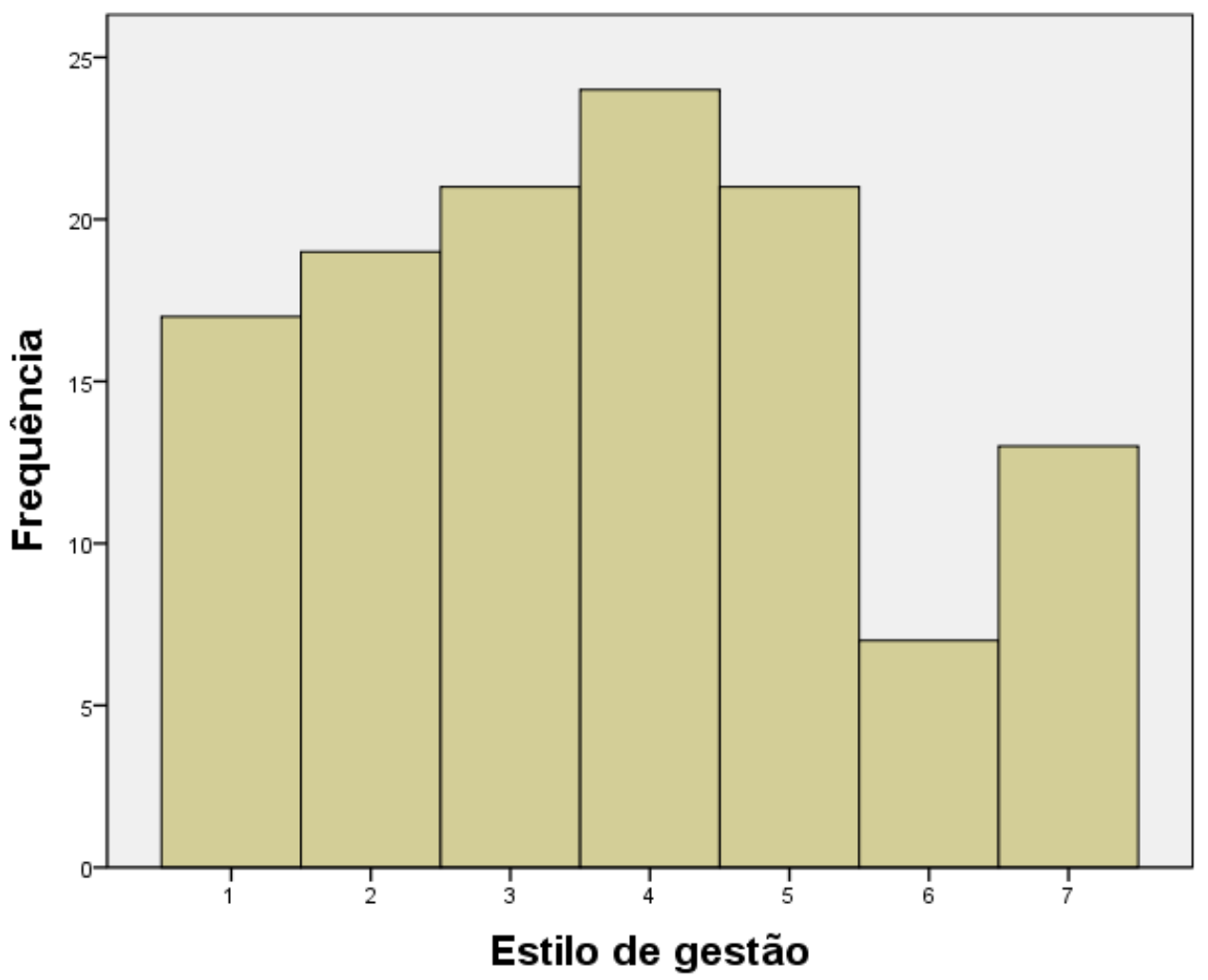

FIGURA 8: Distribuição de frequência do estilo de gestão FONTE: Autores (2016). 


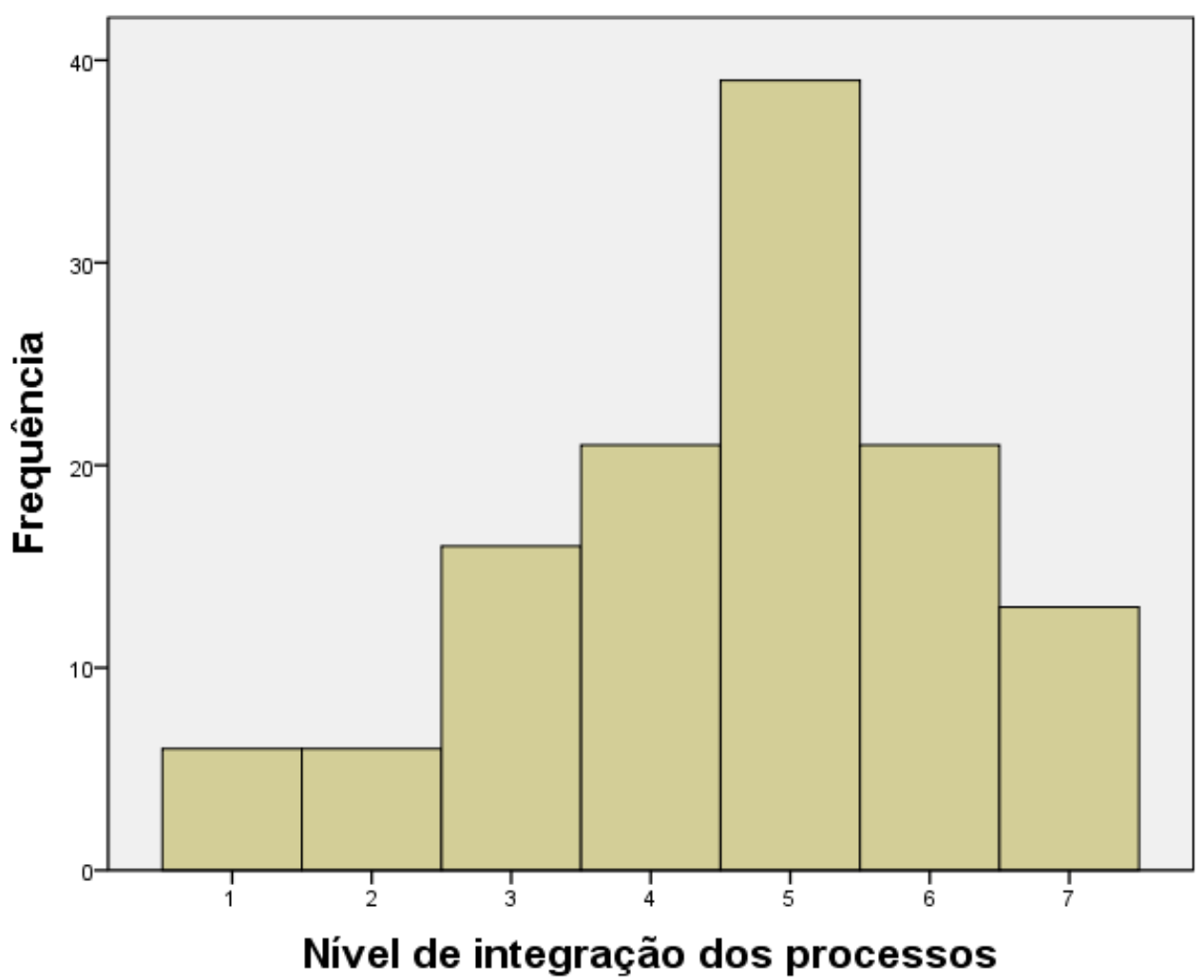

FIGURA 9: Distribuição de frequência do nível de integração entre processos

De acordo com o gráfico da Figura 10, pode-se observar que a maioria das empresas possui controle intensivo sobre as atividades dos funcionários. A escala utilizada varia de nenhum controle (1) a controle intensivo (7). Os resultados estão concentrados entre os níveis 4 a 6 , com destaque para o valor 5 .

No gráfico da Figura 11 é possível observar que as empresas apresentam um elevado grau de autonomia dos funcionários. A escala utilizada varia de 1 (sem autonomia) até 7 (autonomia total). Os valores obtidos se concentram entre 4 e 6 . É possível observar que há uma queda abrupta da autonomia a partir do valor 5 . Isso mostra que há autonomia, mas ela é limitada a um patamar. Ao mesmo tempo em que os funcionários possuem autonomia para lidar com a variabilidade e as imprevisibilidades típicas das atividades da construção, eles também são controlados por normas e parâmetros de desempenho e de qualidade típicas da atividade de construção.

A Figura 12 apresenta os gráficos boxplot das variáveis relacionadas à forma de gestão. Neste grupo as variáveis relacionadas com a autonomia do funcionário, a integração entre processos e o controle sobre as atividades dos funcionários apresentaram uma diferença interquartil pequena. Isso mostra que estas variáveis são bem características do setor e apresentam uma maior homogeneidade entre as empresas. Já a variável que representa o estilo de gestão está mais dispersa. A partir da análise conjunta dos gráficos é possível identificar um nível de integração dos processos e de controle sobre os funcionários alto e consolidado nas empresas do setor. As duas variáveis apresentam valores acima da média e com pouca dispersão. O controle das atividades é inerente ao setor. Apesar do estilo de gestão e a autonomia apresentarem valores de mediana em uma posição intermediária, o estilo de gestão é bem mais variável entre as empresas. A variação da autonomia, por sua vez, é menor entre as empresas do setor. Assim, pode-se afirmar que as empresas do setor da construção civil investigadas neste trabalho apresentam um alto nível de integração de seus processos. Além disso, elas tentam buscar o equilíbrio entre o elevado nível de controle dos funcionários e o alto nível de autonomia das atividades desempenhadas por eles. 


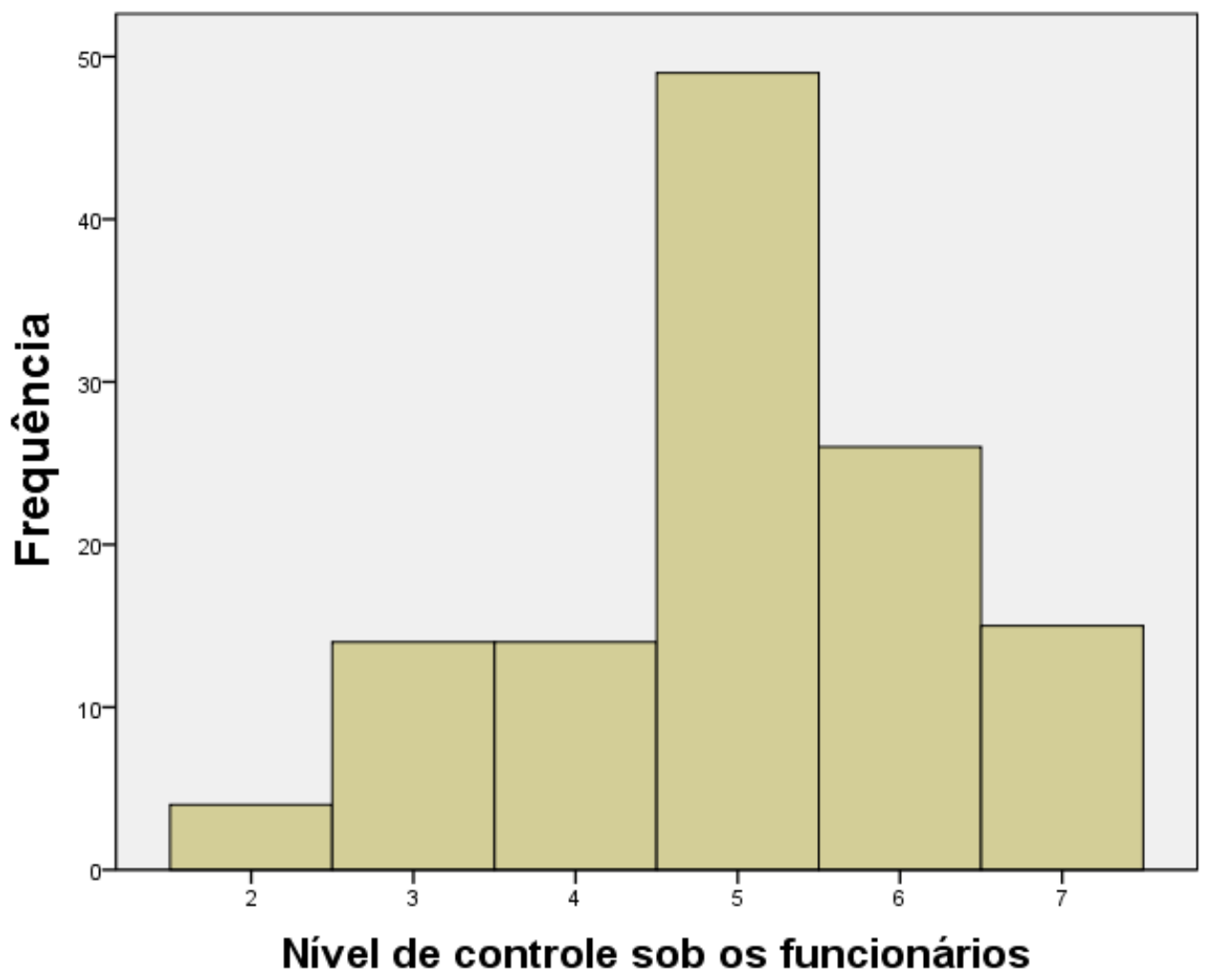

FIGURA 10: Distribuição de frequência do nível de controle sobre as atividades FONTE: Autores (2016).

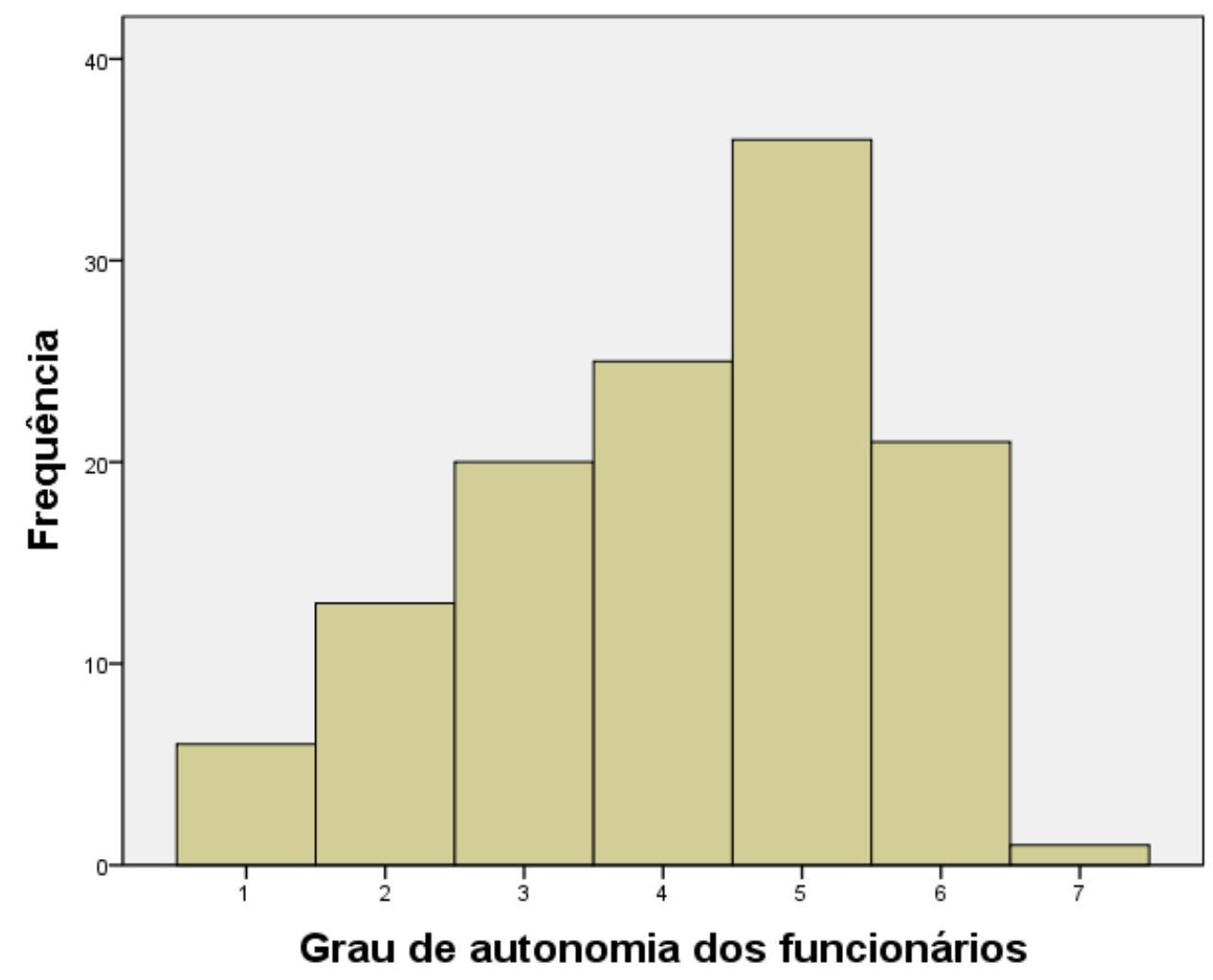

FIGURA 11: Distribuição de frequência do grau de autonomia dos funcionários FONTE: Autores (2016) 


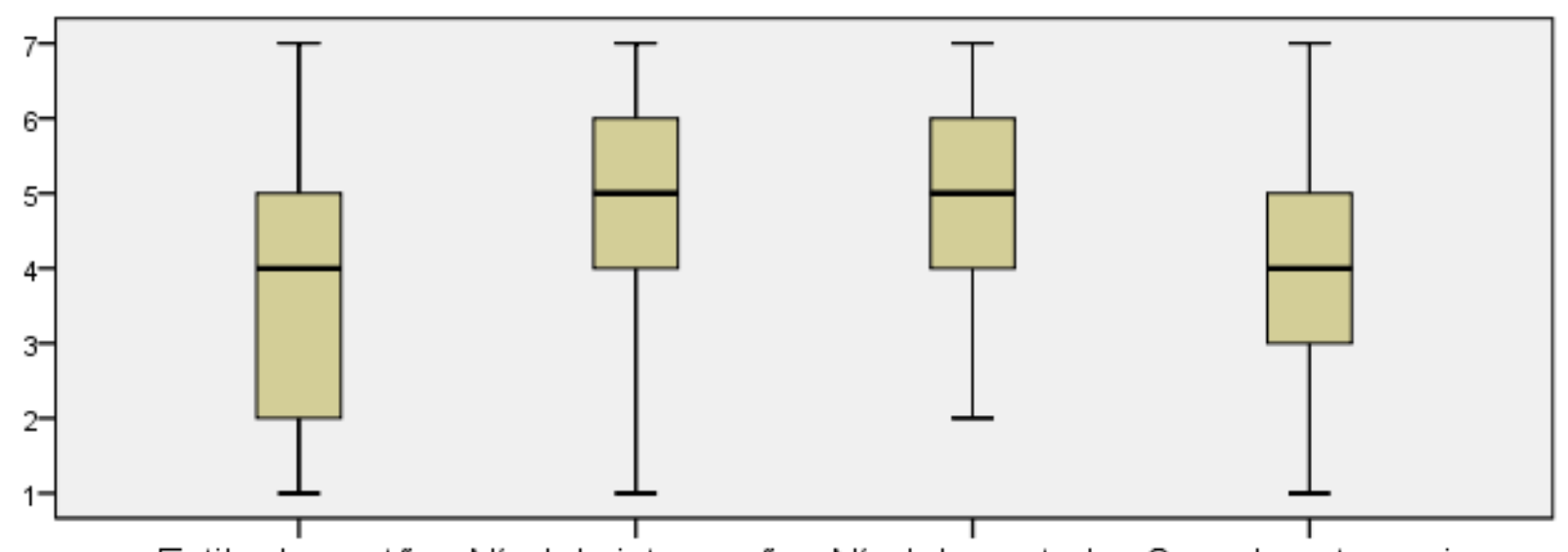

Estilo de gestão Nivel de integração Nivel de controle Grau de autonomia dos processos sob os funcionários dos funcionários

FIGURA 12: Gráficos boxplot das variáveis relacionadas a forma de gestão FONTE: Autores (2016).

4.1.3 Análises das variáveis relacionadas à formação de pessoal

O fator formação de pessoal é composto por três variáveis: média de horas de treinamento por ano, nível de formação dos funcionários e nível de polivalência dos funcionários.

A Figura 13 apresenta o gráfico da distribuição da quantidade de horas de treinamento. A escala varia de "sem treinamento" até "média superior a 12 dias/ano". Observa-se pelo gráfico que há pouco investimento na qualificação dos funcionários. Os dados revelam esse comportamento, mediante a concentração dos valores entre os valores 1 a 4 da escala.

O nível de formação dos funcionários é caracterizado no gráfico da Figura 13. A escala utilizada oscila entre sem formação (1) a maioria com nível superior e pós-graduação (7). Os valores estão concentrados entre os níveis 2 e 5 , com destaque para o valor 4 . O que caracteriza o nível de formação entre baixa e média formação. A baixa formação representa uma característica bem marcante do setor da construção civil.

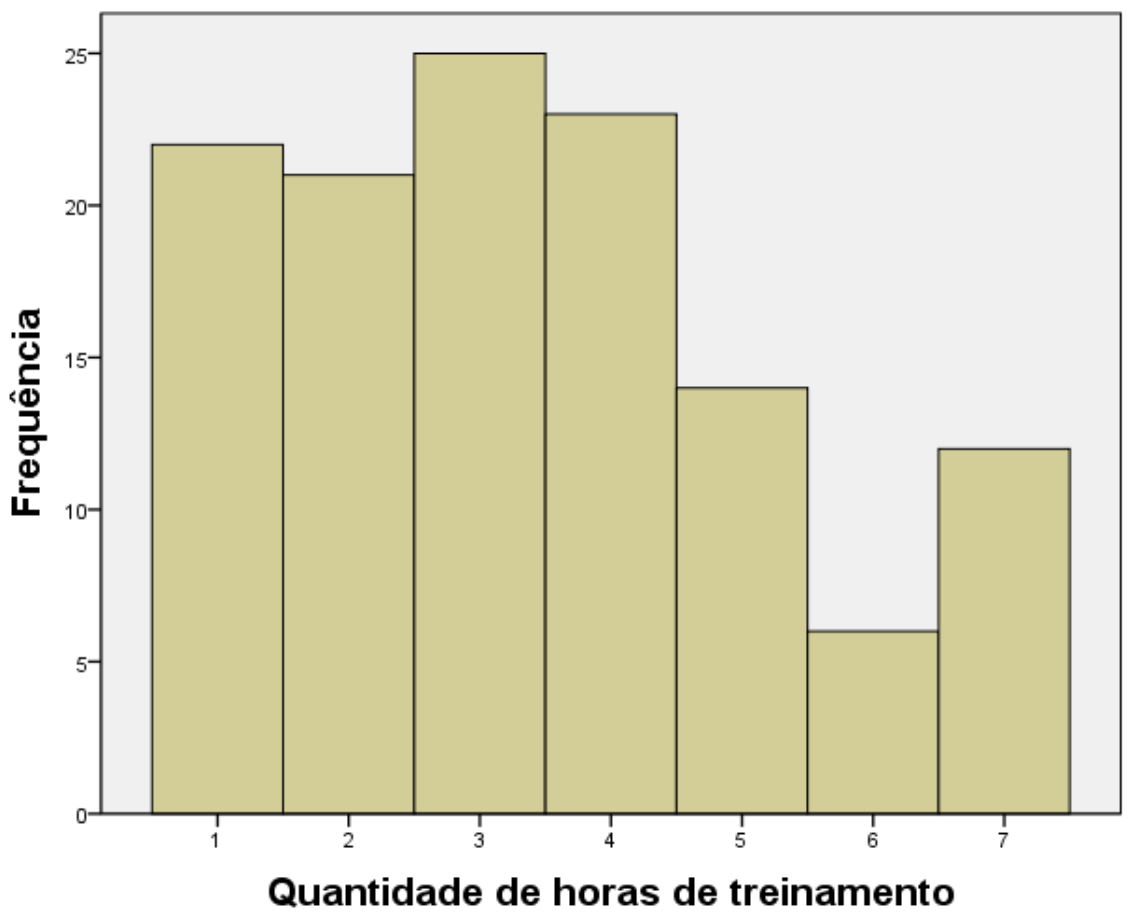

FIGURA 13: Distribuição de frequência da quantidade de horas de treinamento FONTE: Autores (2016). 


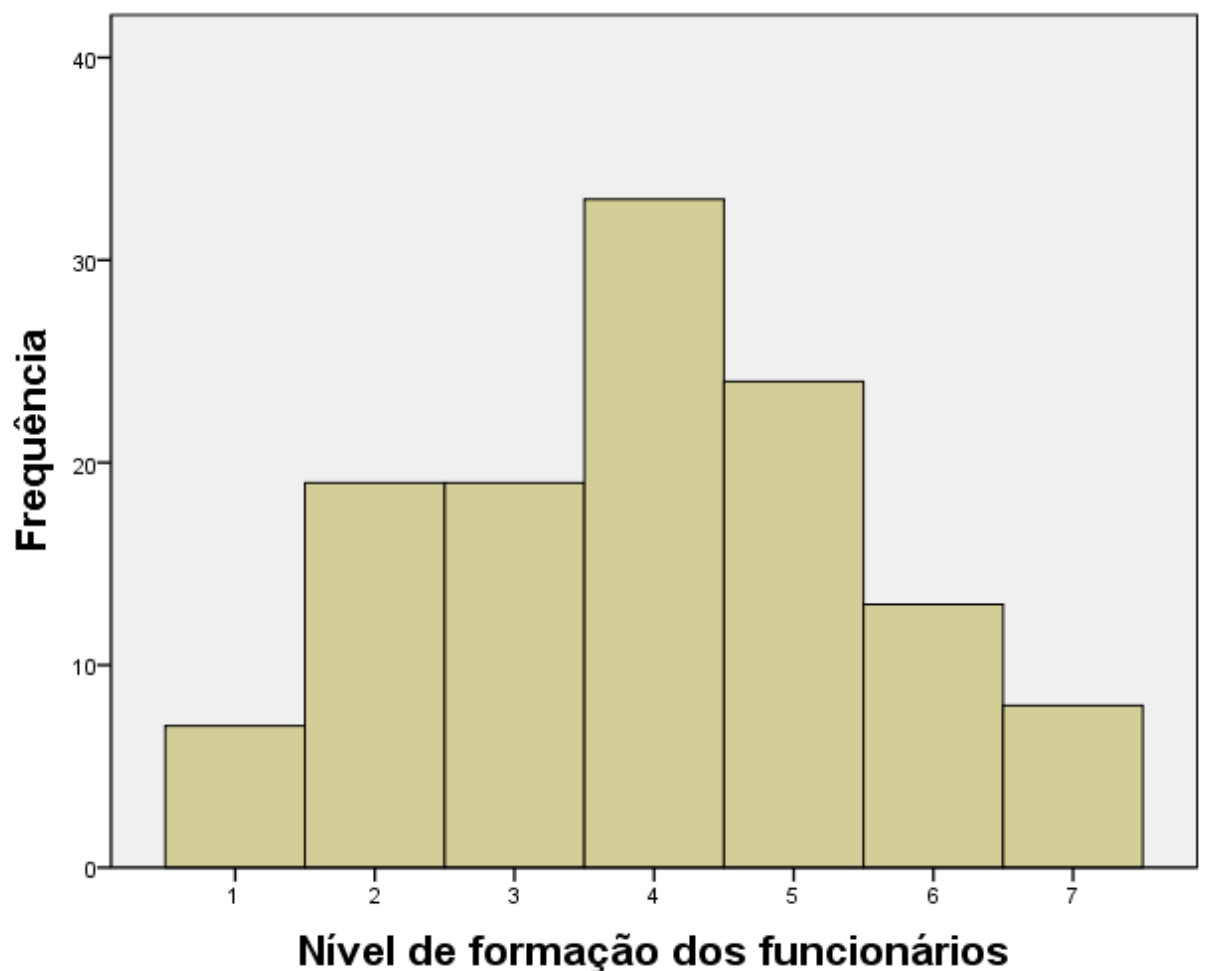

FIGURA 14: Distribuição de frequência do nível de formação dos funcionários FONTE: Autores (2016).

No gráfico da Figura 15, é possível observar que a maior parte das empresas do setor da construção civil apresenta uma forte tendência para a multifuncionalidade dos profissionais. As respostas estão agrupadas entre os valores 4 e 7 da escala.

A Figura 16 apresenta os gráficos boxplot das variáveis relacionadas à formação dos funcionários das empresas. É possível observar que a polivalência é alta e bem definida nas empresas do setor. A formação aparece em um nível intermediário. Entretanto, as horas de treinamento estão em um patamar inferior à média e mais dispersas entre as empresas. As variáveis relacionadas com o nível de formação dos funcionários e nível de polivalência apresentaram uma diferença interquartil pequena. Isso evidencia que no âmbito desta pesquisa, o nível de formação baixo e o nível de polivalência alto dos funcionários é uma peculiaridade do setor.

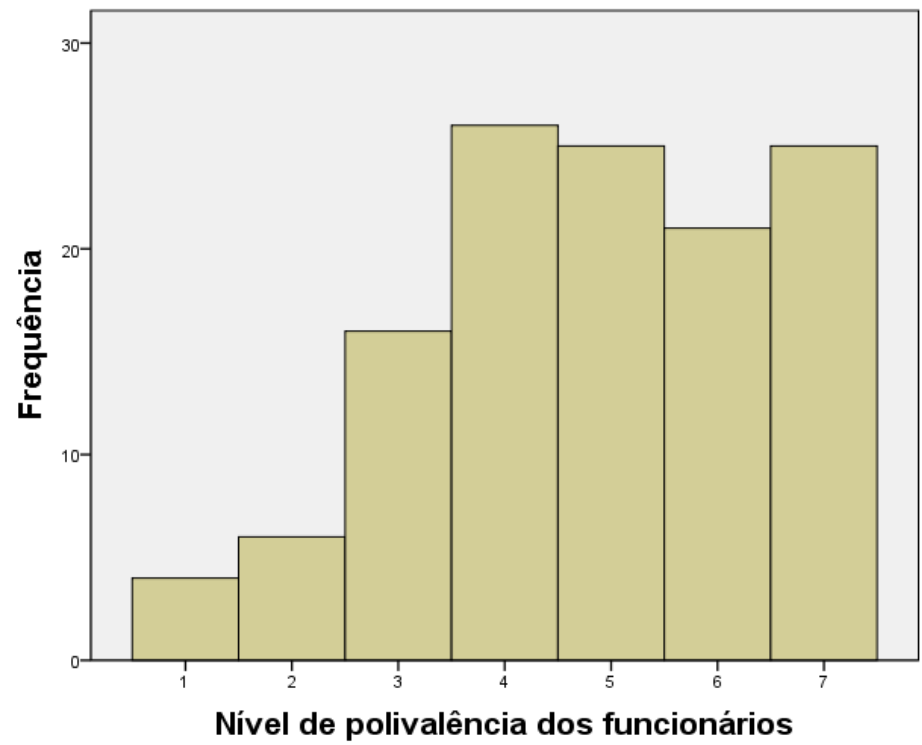

FIGURA 15: Distribuição de frequência do nível de polivalência dos funcionários FONTE: Autores (2016). 


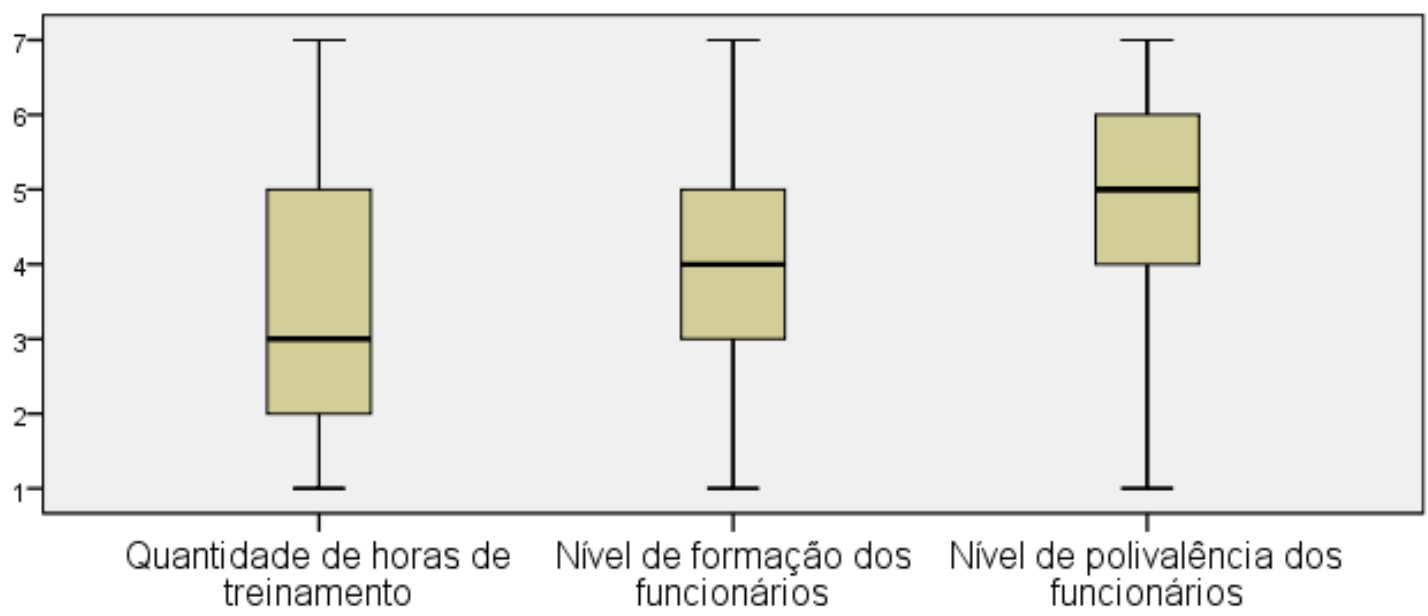

FIGURA 16: Gráficos boxplot das variáveis relacionadas à formação dos funcionários FONTE: Autores (2015).

\subsection{ANÁLISE DAS VARIÁVEIS DEPENDENTES}

O grupo das variáveis dependentes é formado por fatores organizacionais às quais ocorrem em consequência de decisões tomadas pela empresa em relação ao seu modo de se organizar e funcionar. Essas variáveis são subdivididas em relações humanas e flexibilidade.

\subsubsection{Análise das variáveis correlatas às relações humanas}

O fator relações humanas é formado por três variáveis: nível de cooperação entre os funcionários, nível de interação entre os funcionários e o modo como ocorrem às relações entre funcionários (formais ou informais).

Os dados do gráfico da Figura 17 mostram que há uma clara concentração de valores entre as escalas 5 e 6 caracterizando a cooperação dos funcionários de forma positiva. Da mesma forma o gráfico da figura 18 mostra que há um grande nível de interação entre os funcionários das empresas do setor. Os dois gráficos possuem um comportamento muito semelhante. Ambos apresentam concentrações de valores muito próximas de valores entre as escalas 5 e 6.

O gráfico da Figura 19 apresenta o modo de relações entre funcionários. A escala varia de formal a informal. Pode-se observar que as relações apresentam uma tendência de serem mais formais entre os funcionários. Destacando os valores concentrados na escala 4 que representa um nível intermediário nas relações (formais/informais).

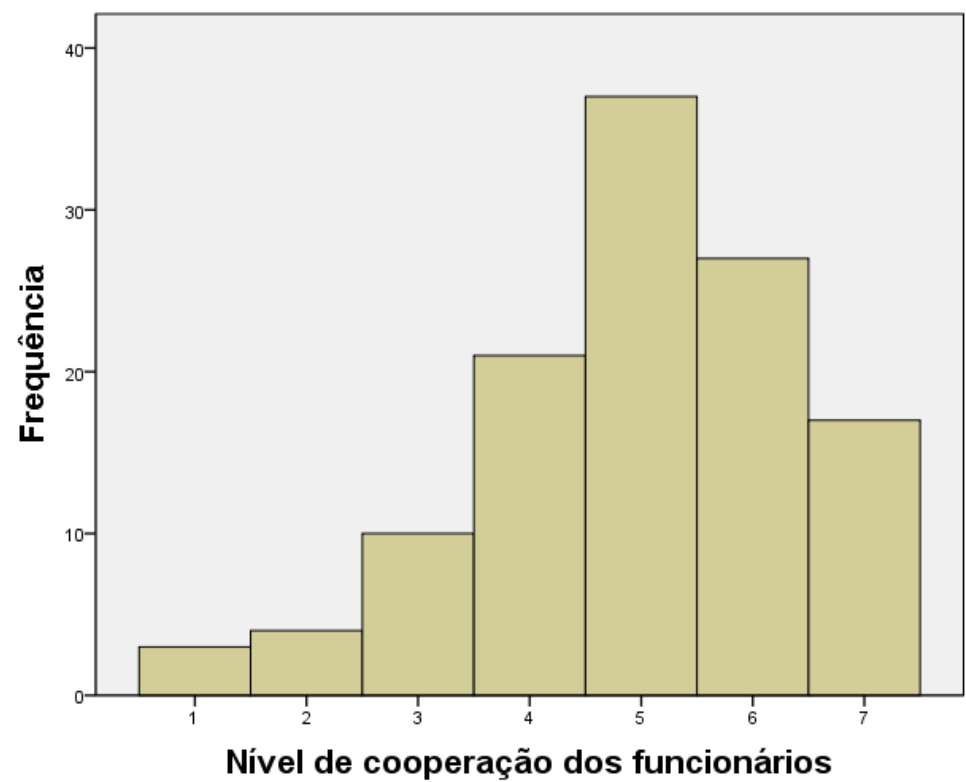

FIGURA 17: Distribuição de frequência nível de cooperação entre os funcionários FONTE: Autores (2016). 


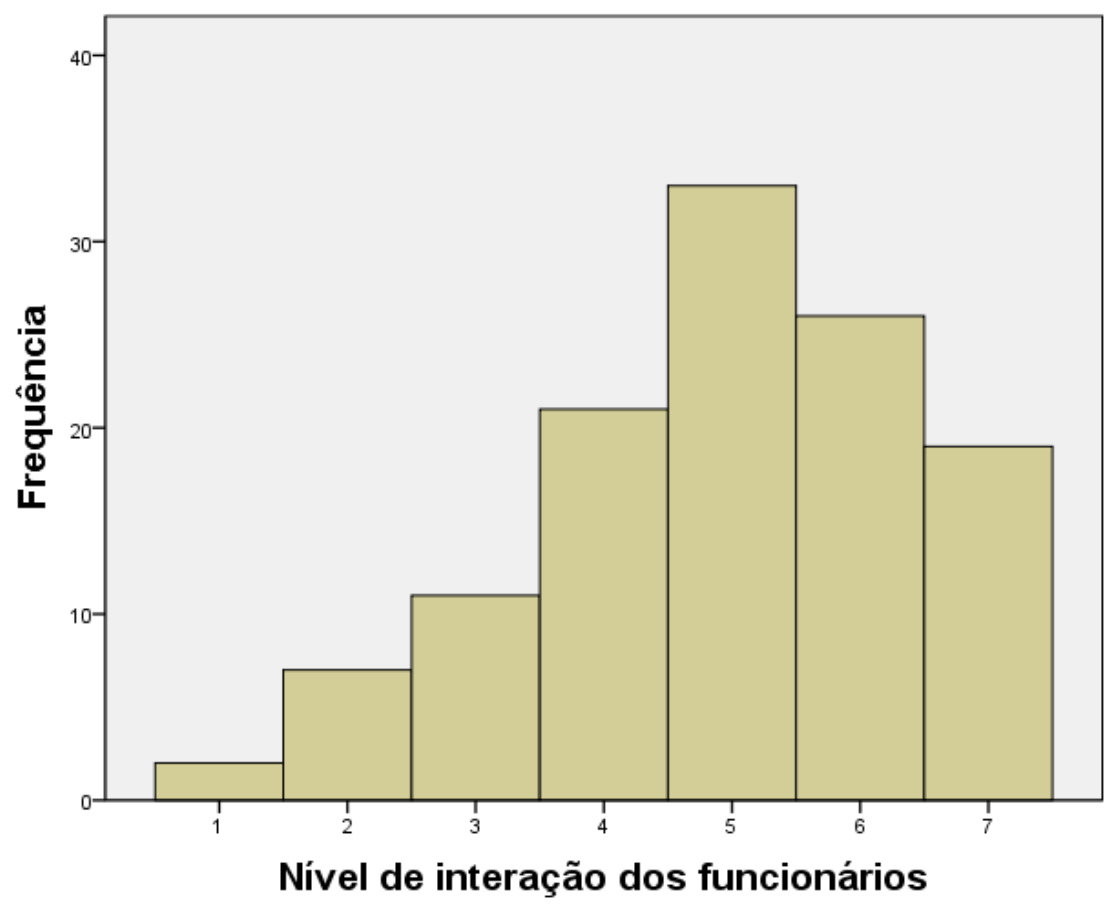

FIGURA 18: Distribuição de frequência nível de interação dos funcionários FONTE: Autores (2016).

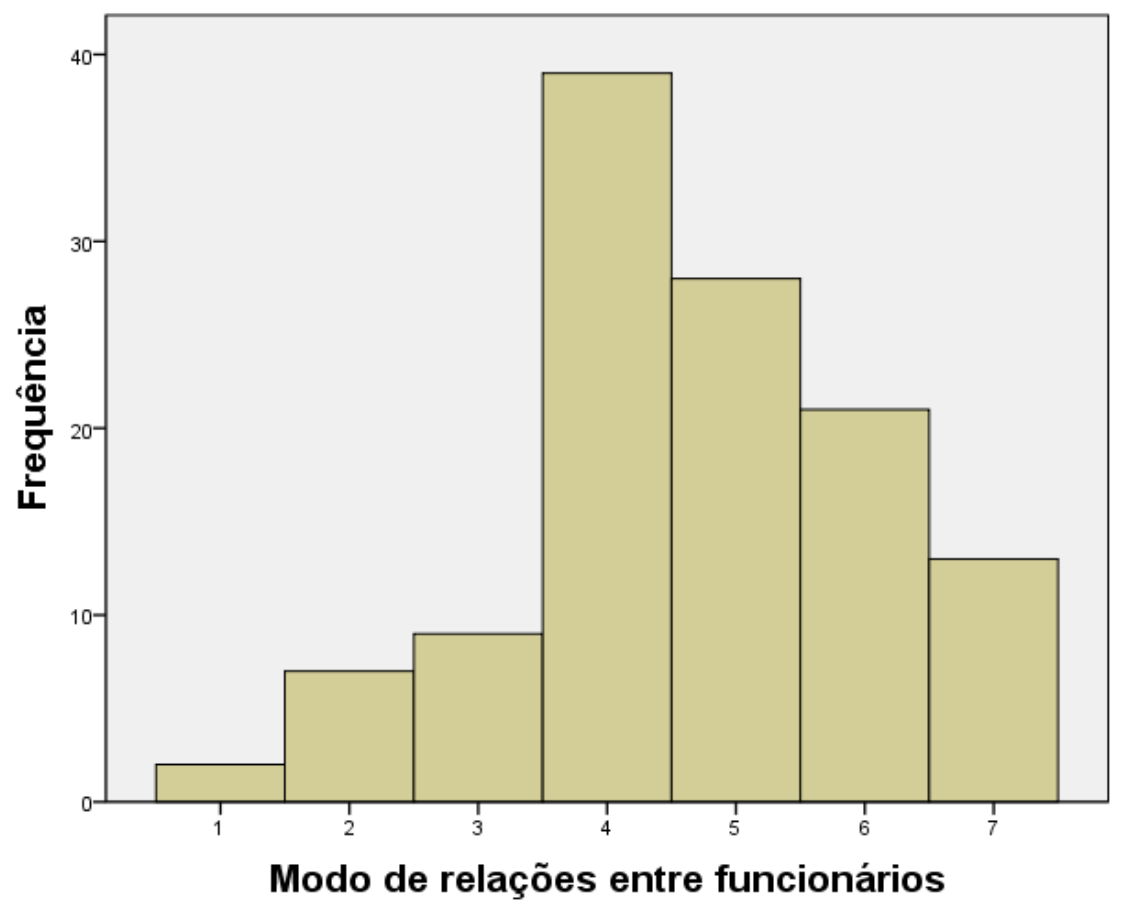

FIGURA 19: Distribuição de frequência do tipo de relação entre os funcionários FONTE: Autores (2016).

Os gráficos da Figura 20 apresentam um resumo do comportamento das variáveis que representam as "relações humanas" nas empresas. É possível observar que comportamento das variáveis é muito semelhante. $O$ que evidencia certa homogeneidade dos relacionamentos. Eles são caracterizados pela forte cooperação e interação entre os indivíduos, e privilegiando as relações formais. 


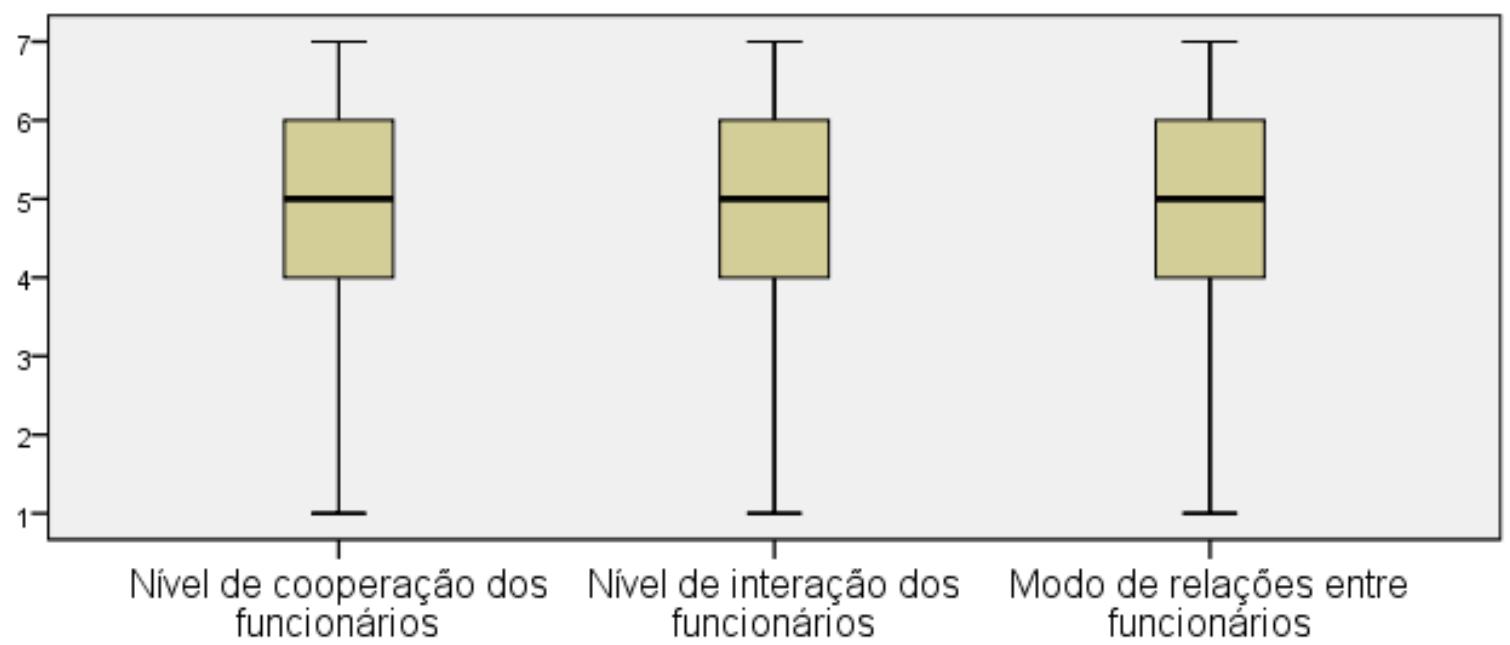

FIGURA 20: Gráficos boxplot das variáveis correlatas às relações humanas FONTE: Autores (2016).

4.2.1 Análises das variáveis relacionadas à flexibilidade

O fator flexibilidade é formado por três variáveis: capacidade da empresa em se adaptar às mudanças do seu mercado, protagonismo em relação a seguir as tendências de mercado ou antecipar-se às mudanças e o tempo de resposta da empresa às demandas de mercado.

O gráfico da Figura 21 apresenta a capacidade da empresa em se adaptar às mudanças. Portanto, observa-se que as empresas pertencentes à construção civil possuem uma capacidade importante de se adaptar a novas situações. Galhano e Nakata (2011) declaram que implementar novas estruturas organizacionais com mais agilidade e com as vantagens do planejamento e participação, resulta em organizações mais competitivas e inovadoras no mercado.

O protagonismo em relação ao mercado está representado no gráfico da Figura 22. Com base na concentração de valores entre as escalas 4 e 5 , observa-se que as empresas estão preocupadas em se antecipar às mudanças. Na perspectiva de Hoss et al. (2010), no momento em que o mercado se define, a organização não será pega de surpresa, tendo que adaptar suas ações de forma apressada para se ajustar às mudanças, se definir as possibilidades de rumos para aguardá-las. Portanto, qualquer situação futura, dentre as quais os gestores presumiram que pudessem acontecer, serão assimiladas com mais tranquilidade, pois já pensaram sobre ela, antes mesmo de acontecer, ou seja, criaram cenários. O que significa que a estratégia pensada como a mais apropriada se encontrava traçada e a organização poderá utilizá-la conforme o plano de ação, com os ajustes que se fizerem necessários.

Finalmente, o gráfico da Figura 23 apresenta o tempo de resposta às demandas de mercado (novos produtos, certificações, tecnologias diferenciadas, etc.). Percebe-se uma concentração de respostas em um nível intermediário de agilidade em relação às demandas de mercado. Esta tendência pode ser justificada pelo aumento da concorrência entre empresas do setor.

Os gráficos da Figura 24 apresentam um panorama do comportamento das variáveis que representam a "flexibilidade" das empresas do setor da construção. Percebe-se que a variável relacionada à capacidade da empresa em se adaptar às mudanças apresenta uma diferença interquartil pequena mostrando uma concentração de valores em um nível intermediário e com uma queda abrupta após o valor da mediana que coincide com o terceiro quartil. As variáveis relacionadas ao protagonismo e ao tempo de resposta se apresentam em uma posição intermediária e com pouca dispersão dos valores. Isso significa que as empresas em estudo não se destacam por uma atuação mais efetiva junto aos seus mercados. As ações são tímidas e numa cadencia baixa em relação à dinâmica do mercado. 


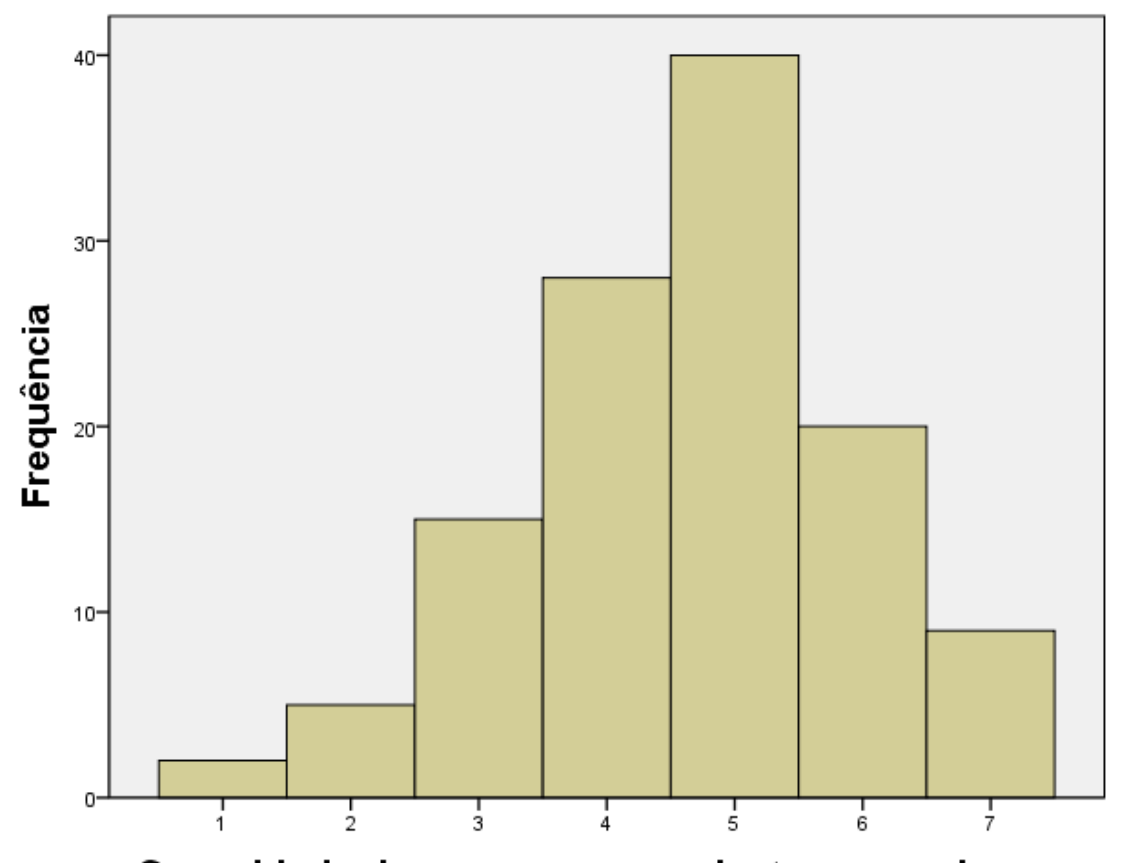

Capacidade da empresa a se adaptar as mudanças

FIGURA 21: Distribuição de frequência da capacidade para se adaptar as mudanças FONTE: Autores (2016).

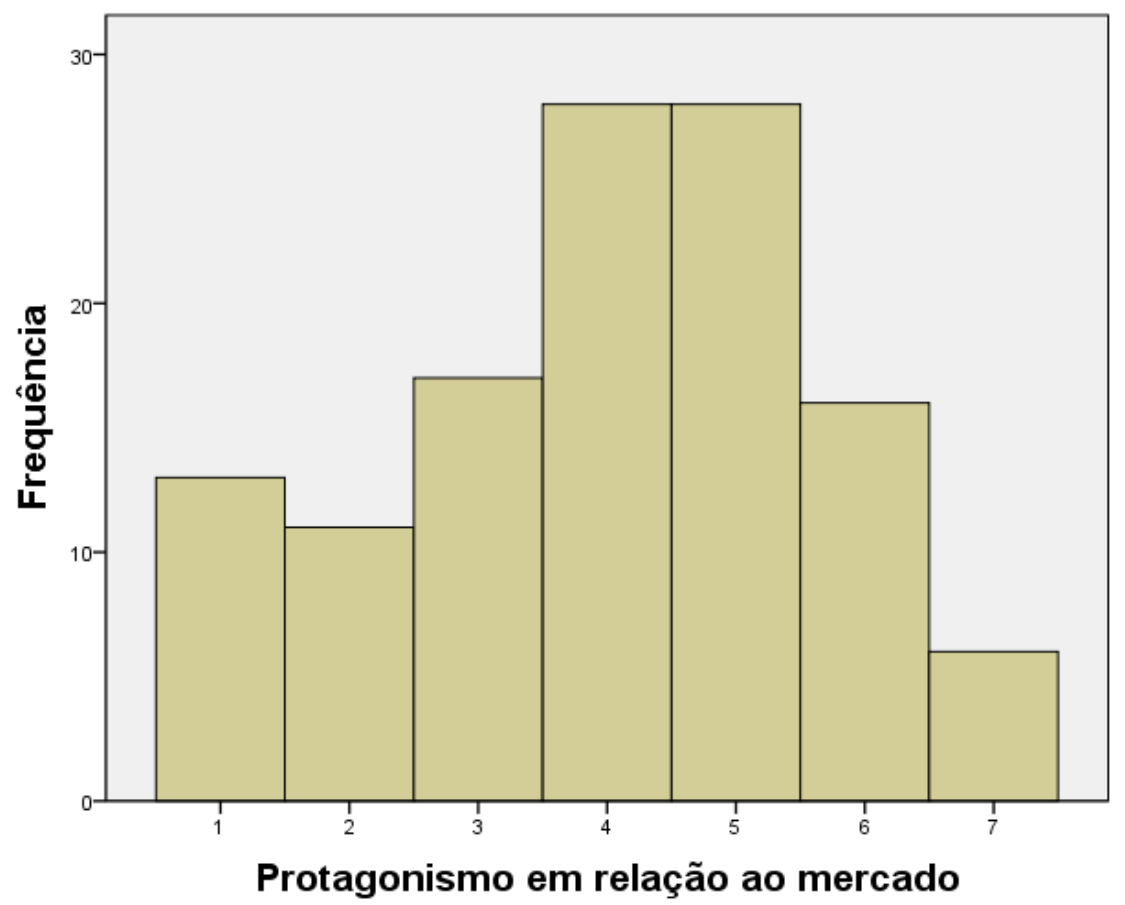

FIGURA 22: Distribuição de frequência em relação ao protagonismo ao mercado FONTE: Autores (2016). 


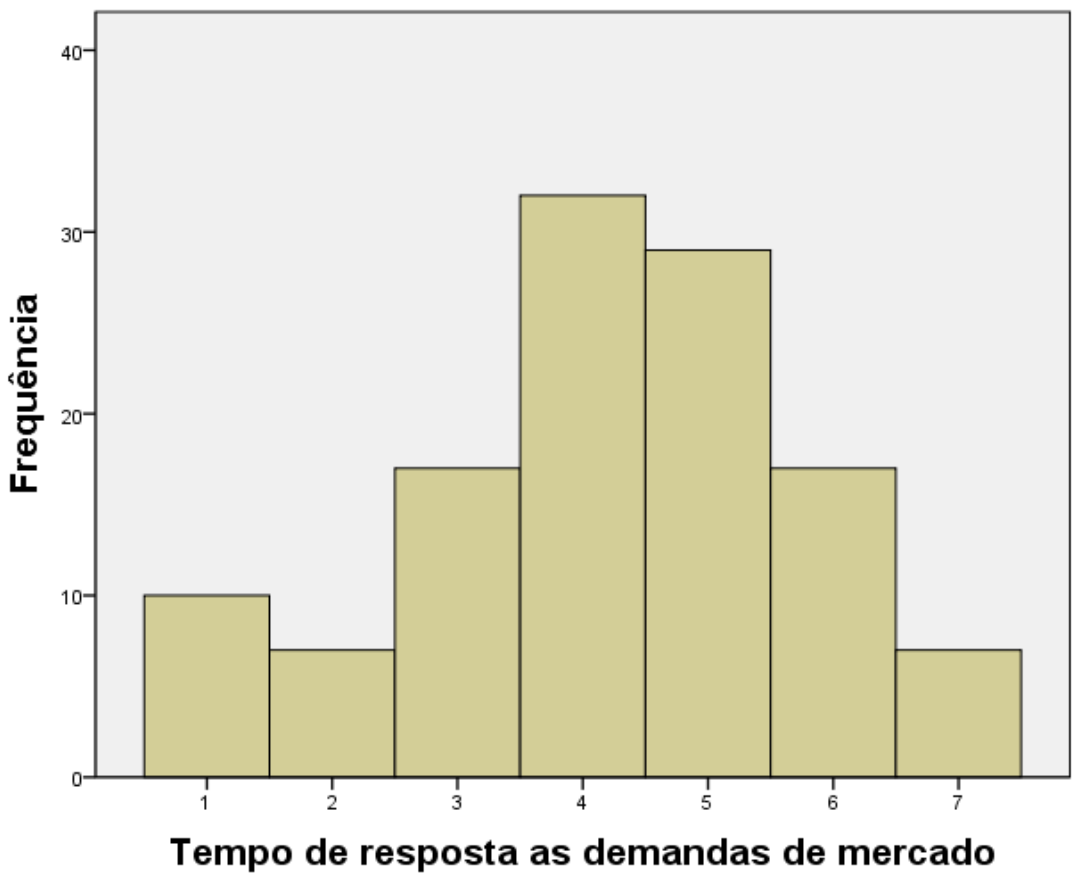

FIGURA 23: Distribuição de frequência em relação ao tempo de resposta FONTE: Autores (2016).

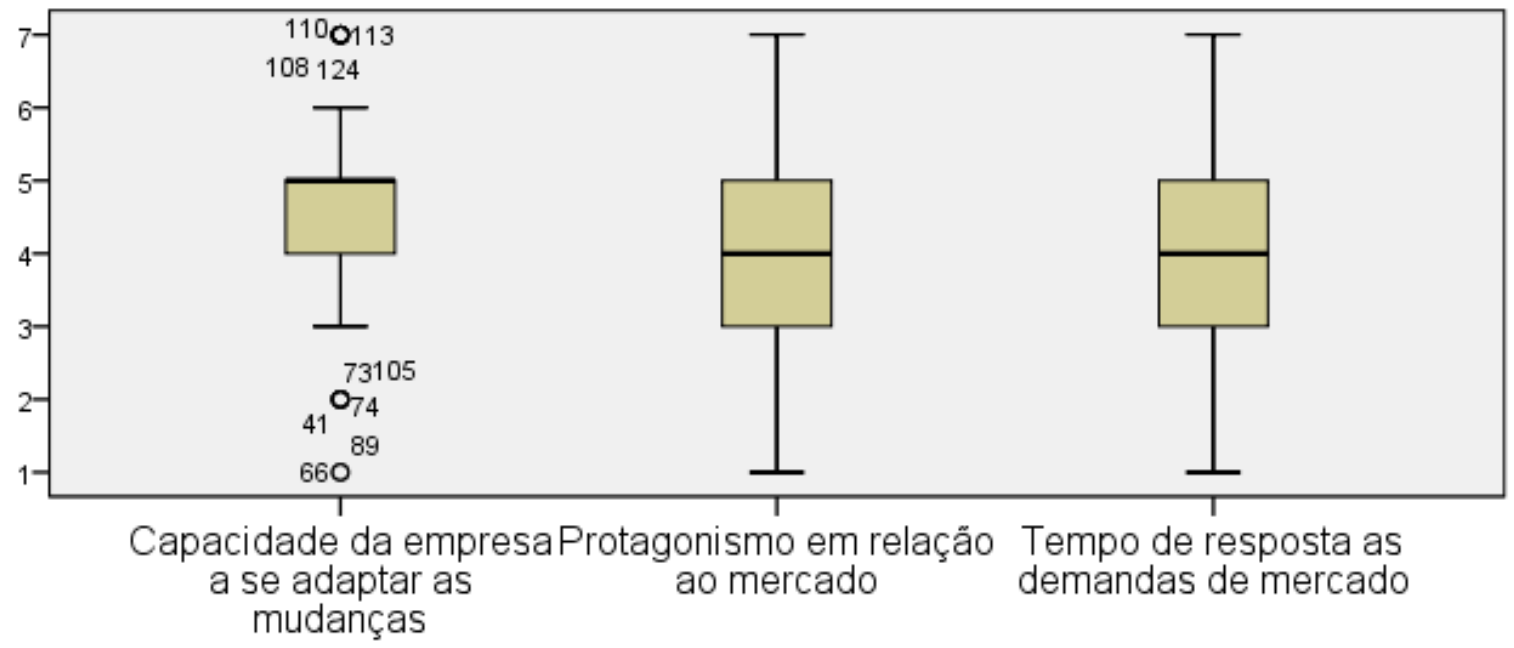

FIGURA 24: Gráficos boxplot das variáveis relacionadas a flexibilidade FONTE: Autores (2016).

\subsection{ANÁLISE DO CONJUNTO DAS VARIÁVEIS}

Com relação à estrutura, a análise das variáveis, possibilitou concluir que as empresas do setor da construção pesquisadas se apresentam como altamente centralizadas, com cargos e funções bem formalizados, elevados níveis de formalização de atividades e processos e bem hierarquizadas. Quanto à forma de gestão, apresentam um estilo que tende ao autocrático, mas com alto grau de autonomia e de interação entre os funcionários. Isso possivelmente em função das necessidades impostas pelas características da atividade da construção. O controle é intensivo sobre as atividades desenvolvidas. Entretanto, em relação à formação de pessoal, existe pouco investimento na qualificação dos funcionários, resultando em um nível de formação que tende a ser baixo. Apesar disso, os funcionários apresentam um alto grau de polivalência.

O comportamento das variáveis referentes ao fator relações humanas demonstra um alto nível de cooperação e interação entre os funcionários. As relações são mais informais. Quanto à flexibilidade, as empresas possuem uma razoável capacidade em se adaptar as mudanças, mas não demostram um protagonismo muito 
elevado, preferindo seguir as tendências do mercado. Isso se refle em um tempo de resposta lento as demandas de mercado.

\section{CONCLUSÕES}

A pesquisa baseou-se em uma amostra de 125 empresas atuantes nos mais diversos subsetores da construção. Ela não representa o universo de todas as empresas brasileiras, mas traz um retrato inicial das principais características que distinguem as empresas do setor da construção.

De forma bem resumida este retrato é caracterizado por organizações bem centralizadas, com cargos e funções bem formalizados, elevados níveis de formalização de atividades e processos e bem hierarquizadas. Com um estilo gerencial autocrático e com um controle intensivo sobre as atividades. Entretanto, pela complexidade da atividade de construção, a execução das atividades apresenta um alto grau de autonomia e de interação. Os funcionários possuem baixa qualificação, mas apresentam um alto grau de polivalência para enfrenta as variabilidades inerentes a atividade. Isso, resulta em um ambiente de trabalho colaborativo e informal. Todos estes aspectos afetam negativamente o protagonismo da empresa em relação ao seu mercado.

Antes de generalizar as críticas ao setor da construção, é preciso ter um diagnóstico mais preciso da situação real das organizações para poder propor com segurança soluções adequadas as reais necessidades do setor. Esse trabalho faz parte de um esforço para tornar mais claro os aspectos relacionados a gestão das empresas do setor da construção a partir de uma pesquisa empírica das características organizacionais das empresas. É neste aspecto que está a sua maior contribuição para a área de gestão e economia da construção.

\section{REFERÊNCIAS BIBLIOGRÁFICAS}

AGUIAR, B.; CORREIA, W.; CAMPOS, F. Uso da Escala de Diferencial Semântico na Análise de Jogos. Universidade Federal de Pernambuco. Salvador, 2011.
BENSON, L. T. H. Organizational flexibility management in construction. Thesis. National University of Singapore, 2010.

BUSSAB, W. O.; MORETTIN, P. A. Estatística Básica. 7ạ edição, 1a reimpressão, Ed. 2011

CHANG, S. J.; CHOI, U. Strategy, Structure and Performance of Korean Business Groups: A Transactions Cost Approach. The Journal of Industrial Economics. P. 141-158, 1988

CHEUNG, S. O.; WONG, P.; LAM, A.L. An investigation of the relationship between organizational culture and the performance of construction organizations. Journal of Business Economics and Management, v. 13, n. 4, p. 688704, 2012.

DIKMEN, I.; BIRGONUL, M. T.; KIZILTAS, S. Prediction of Organizational Effectiveness in Construction Companies. Journal of Construction engineering and Management. Feb. 2005. 131:252-261, 2005.

GALHANO, P.P.P.; NAKATA, L.E. Gestão do Conhecimento em Estruturas Inovativas: Um Estudo de Caso. Dimens. empres. - Vol. 9 No. 2, Julio - Diciembre de 2011, p. 3547. São Paulo, 2011.

GUEDES, T. A. Projeto de ensino. Aprender fazendo estatística. 2005. Disponível em: <http://www.each.usp.br/rvicente/Guedes etal Estatistica_Descritiva.pdf>. Acesso em: 01 jan. 2011.

HAIR, JR., J. F.; BABIN, B.; MONEY, A. H.; SAMOUEL, P. Fundamentos de métodos de pesquisa em administração. Porto Alegre: Bookman, 2005

HALL, R. H. Organizações. Estruturas, processos e resultados. 8. ed. São Paulo: Pearson Prentice Hall, 2004.

HANDA, V.; ADAS, A. Predicting the Level of Organizational Effectiveness: a Methodology for the Construction Firm. Construction Management \& Economics. V. 14, n. 4, p. 341-352, 1996.

HARRIS, F; McCAFFER, R. Modern Construction Management. Wiley. $7^{\text {th }}$ ed. 576p. 2013.

HOSS, O.; ROJO, C. A.; GRAPEGGIA, M. Gestão de ativos intangíveis: da mensuração à competitividade por cenários. São Paulo: Atlas, 2010

INSTITUTO BRASILEIRO DE GEOGRAFIA E ESTATÍSTICA. Pesquisa anual da indústria da construção. V.21. Rio de Janeiro, 2011. Disponível em: <http://loja.ibge.gov.br/pesquisa-anual-da-industria-daconstruc-o-2011.html>. Acesso em 25 ago. 2013.

INSTITUTO DE EDUCAÇÃO TECNOLÓGICA. Construção Civil: mercado cresce no país e aponta grandes desafios no setor. Comunicação IETEC. Disponível em: Http://www.techoje.com.br/site/techoje/categoria/deta Ihe_artigo/1157. Acesso em 24 mar. 2014. 
KIM, S. Organization and Managerial Environment of the Korean Construction Industry. Construction Management \& Economics. V. 15, n. 5, p. 409-419, 1997.

LANNES JR, A.; FARIAS FILHO, J. R. O conceito Lean Green de construção: proposta de integração dos modelos Lean Construction e Green Building, aplicado á indústria da construção civil, subsetor edificações. XXIV Encontro Nacional de Engenharia de Produção. Florianópolis, 2004

LANSLEY, P. Analysing construction organizations. Construction Management and Economics. v. 12, n. 4, p. 337-348, 1994.

MILONE, G. Estatística geral e aplicada. São Paulo: Pioneira Thomson Learning, 2004.

MINTZBERG, H. Criando Organizações Eficazes: estrutura em cinco configurações. São Paulo: Atlas, 2003.

OZAKI, A. M. Estrutura organizacional para a realização de negócios eletrônicos em empresas tradicionais: um estudo de caso. Dissertação (Mestrado em Administração). Universidade de São Paulo, São Paulo, 2003.

PASQUALI, Luiz. Psicometria: teoria dos testes na psicologia e na educação. Vozes, 2009.

PRESCOT, R. Em alerta: o baixo crescimento do PIB e os indicadores macroeconômicos vem afetando a construção civil, mas isto não significa que o setor esteja diante de uma crise. Revista Construção e Mercado. São Paulo. N. 156 - Julho 2014. São Paulo: PINI, 2014.

SAMARTINI, A.L.S. Comparação entre métodos de mensuração da importância de atributos em produtos e serviços. GV - pesquisa. São Paulo, 2006.

SANT'ANNA, A. S. KILIMNIK, Z. M.; CASTILHO, I. V. Profissionais mais competentes, políticas e práticas de gestão mais avançadas. RAE Revista de Administração de Empresas, São Paulo, v. 7, n. 1, p. 1-26, 2008.

SANTOS, Rafael P. C. Engenharia de processos: análise do referencial teórico-conceitual, aplicações e casos. Tese (Doutor em Ciências em Engenharia de Produção) Universidade Federal do Rio de Janeiro, Rio de Janeiro, 2002.

SHIRAZI, B.; LANGFORD, D. A.; ROWLINSON, S. M. Organizational Structures in the Construction Industry. Construction Management \& Economics. V. 14, n. 3, p. 199-212, 1996.

VASCONCELLOS, E.; HEMSLEY, J. R. Estrutura das organizações. 4. ed. São Paulo: Cengage Learning Edições, 2002.

VASCONCELLOS, Eduardo. Estrutura das organizações. 2. ed. São Paulo: Pioneira, 1989. p.208.

WOODWARD, J. Industrial Organization: Theory and Practice. Oxford University Press, London. 1965.
ZAYED, T.; ELWAKIL, E.; AMMAR, M. A framework for performance assessment of organizations in the construction industry. International Journal of Architeture, Engineering and Construction. Vol 1, No 4, 199-212. December, 2012. 